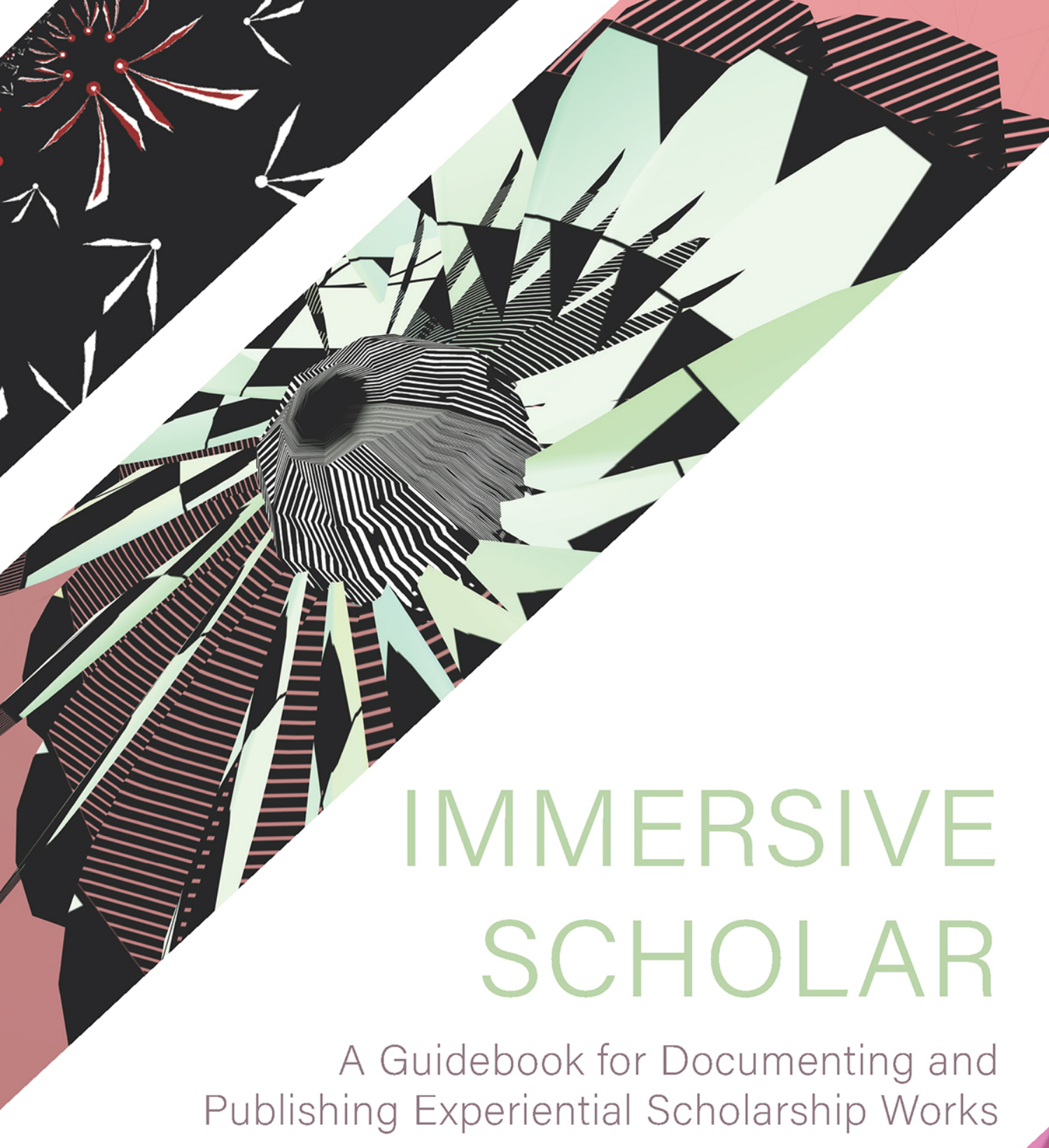


IMMERSIVE SCHOLAR 
This page intentionally left blank 


\title{
IMMERSIVE SCHOLAR
}

\author{
A Guidebook for Documenting and \\ Publishing Experiential Scholarship Works
}

Abigail E. Mann and Micah Vandegrift With Essays from Abigail Feldman and Cynthia Rosenfeld 
(C) 2021 North Carolina State University Libraries

Suggested citation: Mann, Abigail E and Micah Vandegrift.

Immersive Scholar: A Guidebook for Documenting and Publishing Experiential Scholarship Works.

DOI: https://doi.org/10.5149/9781469664286_Mann

This work is licensed under a Creative Commons CC BY license. To view a copy of the license, visit http://creativecommons.org /licenses.

ISBN 978-1-4696-6427-9 (paperback)

ISBN 978-1-4696-6428-6 (open access ebook)

Cover design by Abby Vandegrift, abbyvandegrift.rocks.

Contributions:

Abigail Mann (ORCID: 00oo-ooo2-4108-3573) wrote the original draft and performed review and editing.

Micah Vandegrift (ORCID: oooo-ooo1-8429-7697) conceptualized the project and performed review and editing.

Abigail Feldman (ORCID: 0ooo-0oo2-3172-4218) investigated and wrote original reflections.

Cynthia Rosenfeld (ORCID: oooo-ooo1-7270-4910) investigated and wrote original reflections. 
1 Introduction

7 What Is an Aesthetic of Access? - Abigail Feldman

9 A Rhetorical Framework of Disruption, Recovery, and CareCynthia Rosenfeld

CHAPTER 1: CREDIT

11 Principle

11 In Practice

11 Case Study from Immersive Scholar

13 Discussion

17 Reflections

17 Contributorship_Abigail Feldman

19 Disruption, Recovery, and Care: ContributorshipCynthia Rosenfeld

CHAPTER 2: DECOUPLE

23 Principle

23 In Practice

24 Case Study from Immersive Scholar

25 Discussion

31 Reflections

31 Decoupling-Abigail Feldman

32 Disruption, Recovery, and Care: Decouple-Cynthia Rosenfeld

CHAPTER 3: DOCUMENT

37 Principle

37 In Practice

37 Case Study from Immersive Scholar

40 Discussion

44 Reflections

44 Workflow Transparency: Documentation-Abigail Feldman 
45 Disruption, Recovery, and Care: Workflow TransparencyCynthia Rosenfeld

CHAPTER 4: COMMUNICATE

51 Principle

51 In Practice

52 Case Study from Immersive Scholar

54 Discussion

59 Reflections

59 Communication to Peers-Abigail Feldman

6o Disruption, Recovery, and Care: Peer CommunicationCynthia Rosenfeld

CONCLUSION

65 Reflections

65 Communication to/with Public_-Abigail Feldman

67 Disruption, Recovery, and Care: Communication with Publics-Cynthia Rosenfeld

71 APPENDIX A

Testing Guidelines for Immersive Digital Applications

Walt Gurley

73 APPENDIX B

Raleigh Statement on Good Practices for

Developing Experiential Scholarship Projects

Immersive Scholar Cohort 


\section{$\mathbf{T}$} his guidebook offers a set of practical approaches and theoretical underpinnings to experiential scholarship. "Experiential scholarship" is a broad umbrella under which can be placed data visualization, digital humanities, digital scholarship, expansive publishing, experimental scholarship, immersive experiences, large-scale visualization, and information visualization, as well as many other recent transformative approaches to scholarship. We define it as a mode of creativity, production, and dissemination informed by academic knowledge, presented in multitudinous invitational forms (exhibitions, websites, pedagogical frameworks, immersive pieces, documentation, public programs, etc.), foregrounded by an aesthetic of access, well-documented for posterity, and inclusive of and adaptable to a particular community's experience(s). Much ink has already been spilled over it: from the theoretical side, the value it adds to the academy and knowledge output, from the practical, questions of how to do and deliver it.

This text starts from the assumption that experiential scholarship is at a maturity point such that production does not end with that initial display, be it a website, an installation, or a public performance. Once the digital or visual aspect has been achieved, how do such works fit into larger scholarly and public ecosystems? How are they integrated into the established scholarly record, and how do scholars ensure an afterlife in which the work of the display enters the public sphere? And how can libraries help to achieve these goals? The answers, we hope, can be found in the following chapters.

This guidebook is focused on communicating experiential scholarship to various stakeholders. It starts from the assumption that there is a need for validation through publication to establish authority in both scholarly and public spheres, but that in experiential scholarship, credit, for both nontraditional but vital roles and for work developed in a form and format that may be less familiar to peers and assessment committees, must be clearly communicated. It argues that there is a need for defined practices and language 


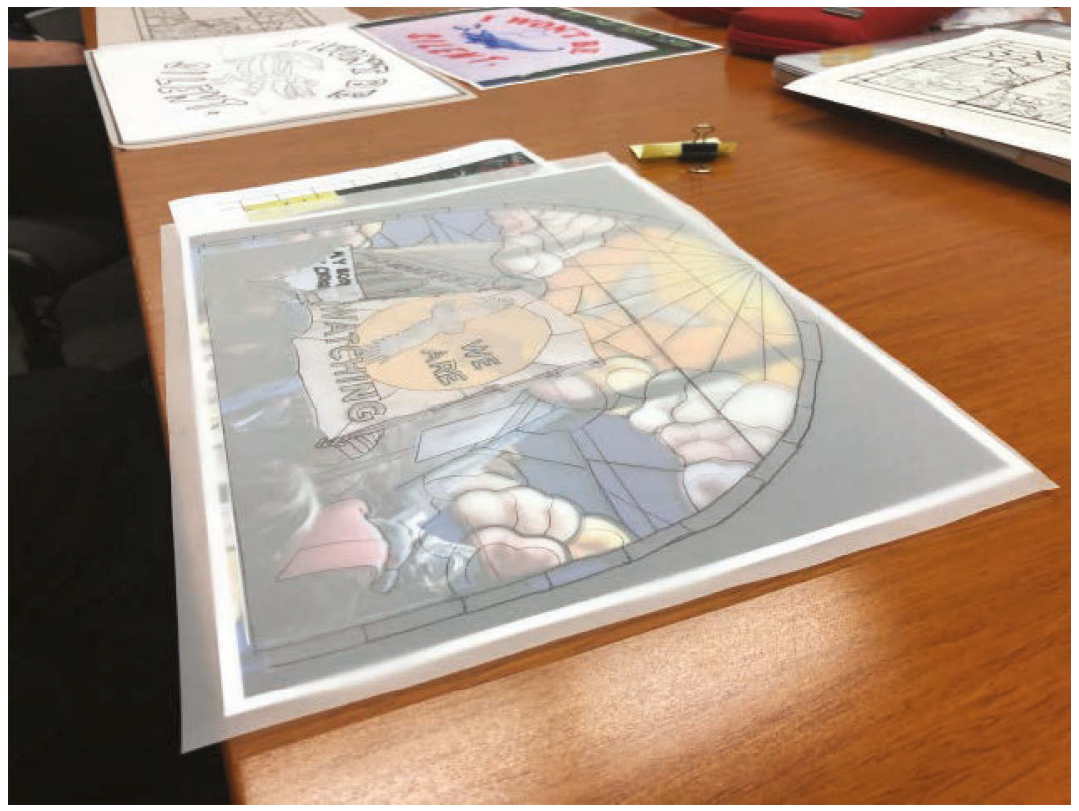

Paper prototype for Liss LaFleur's digital stained glass window project titled "Coded Glass." Photograph by Micah Vandegrift

that allow recognition and evaluation. In a word, we seek documentation: of the form, labor, audiences, and effects.

It is easy to say, yes, we should track these efforts and ensure recognition, but what does this mean in practice, especially for a librarian who is supporting experiential scholarship among many other assigned duties? Below we offer specific principles and practices for what we see as vital centers of validation and authority: assigning credit, decoupling outputs, documenting workflows, and communicating to peers. Each section offers recommended practices for achieving those principles, case studies drawn from the Andrew W. Mellon Foundation-funded Immersive Scholar grant project, and integration of these experiences with the larger critical discussion. Additionally, we are pleased to include reflection essays alongside each chapter, authored by Abigail Feldman and Cynthia Rosenfeld, as products of a series of philosophical, practical, and procedural discussions between the Immersive Scholar team and members of the Virtual Martin Luther King Jr. Project. Feldman's and Rosenfeld's reflections provide a wider, although still local, 
frame of reference for the tenets of experiential scholarship that we propose herein.

The end goal of validation and authority is, of course, communication, both to the public and to peers in the academy. But in thinking about how to effectively communicate to these groups in ways that ensured both validation and authority, we returned over and over to issues of contributorship, decoupling, and documentation. Thus, this guidebook might be seen as operating in two modes. In looking at forms of communication, we focus primarily on the practical, offering principles, specific language, and practices for targeting communications. Far before any communication can happen, however, decisions must be made about contributorship, the modes and media of display and dissemination, and the workflows for creating documentary objects. In "traditional" scholarly communications these decisions are so encoded as to be invisible: they are the expectations of the field. If experiential scholarship both offers and demands new audiences, however, these choices must be made visible and deliberate. Thus our discussion both situates the issue within contemporary discussions and looks at how the experiences of the Immersive Scholar program defined and refined some of these needs.

One of our guiding principles is the action that we call "decoupling," or affirming that each "part" of a project can stand alone and that different audiences may take different paths through the collected artifacts. This guidebook, we hope, acts in a similar way. While it certainly can be read linearly, it is designed to meet the needs of different users in different ways. A librarian facilitating various experiential scholarship projects may find it useful to start at the practices and look at the case studies for needed examples. Alternately, they may find it useful to start with the case studies and discussions and backtrack to the derived principles. Secondary sources have been added throughout these sections, not as necessary reading but as immediately available enhancement. It may be useful to share a background section with a faculty member resistant to spending time on mapping contributorship or an administrator unsure about the value of supporting experiential scholarship in the university.

One of the advantages of working within a nascent field is the opportunity to closely scan the majority (though certainly not all!) of the extant literature and make conscious choices about what to build on and what further needs could be met. We have relied heavily on a number of foundational texts and used them both to inspire our content and point to not yet trodden paths. 
One difference that we noted from the start was the perceived audience of our guide. Most of the existing guides are aimed at people already deeply immersed in one particular field of experiential scholarship, which of course makes sense. Yet we imagined another audience-the library professional working with multiple faculty members all exploring different approaches. While this professional may indeed become a master of many, they definitively must be a jack of all trades. Indeed, librarians frequently end up serving as project managers to experiential scholarship projects, not necessarily because they have the training to do so, but because they are more aware of the many requirements of such a project than anyone else around. There are many manuals on library-based project management out there. In this guidebook we discuss three models that shaped our thinking both to highlight them as useful — we certainly urge turning to them for particulars — but also to define our own approach as "project development."

In some ways, then, our approach might be termed a "goldilocks" approach. Thinking about the needs of this imagined librarian, we sought to add more "how" and "why" to some elements and less to others, while happily helping ourselves to many of the approaches. For instance, The London Charter for the Computer-Based Visualization of Cultural Heritage clearly lays out the pressing need for not just "methodological rigour" but "a means of achieving widespread recognition for this method." Like the writers of the charter, we found defining distinct areas and articulating principles deeply useful and would argue for the applicability of many of these principles to various forms of experiential projects. Yet in reading, we often found ourselves agreeing with the principle but unsure how to enact it. Like the London Charter, Duke University's A Framework for Expansive Publishing assumes a particular approach to experiential scholarship: in their case, the academic monograph. ${ }^{2}$ Both of these texts assume a deep knowledge of a particular field, one that the imagined librarian will not always have-she may be working with a faculty member on data visualization of fractals in the morning and geospatial mapping of tweets in the afternoon. We sought to verbalize what seemed axiomatic to those immersed in their fields, focusing on the principles and practices in specific, concrete language, delineating practices to back up the overarching approach.

Formally, we also felt that the text heavy, linear "book" form was less useful to the jack-of-all-trades librarian, so we conceived this guide as a "choose your own adventure." As we note above, we hope the sections of each chapter 
can be approached as useful elements. At one point, just the principles might be helpful, at others, a case study may offer a useful way to think about a project. We drew here upon the modular approach in Wired! Lab's Visualizing Objects, Places, and Spaces: A Digital Project Handbook. Aimed at a beginner audience, the "researchers and instructors in the early stages of digital project development," their document is "design[ed] to fill the gap between platform-specific tutorials and disciplinary discourse in digital humanities." Divided by project types and stages, this handbook is a tremendous resource in choosing the right platform and knowing why, as well as outlining the process of project development that we echo and affirm. Yet we also contend that planning for the scholarly bonafides of experiential scholarship must be baked in from the very beginning: our guide, then, complements technical "how" concerns with philosophical "whys."

Practically, as an output of the Immersive Scholar project, this guidebook selfishly seeks to pull together the knowledge we gained through the project. Three documents form the backbone of this guidebook: Abigail Mann's "Keywords for Discussing New Scholarship for Tenure and Promotion" and "Supporting New Scholarship: How and Why" and the "Raleigh Statement on Good Practices for Developing Experiential Scholarship Projects." Mann's research and the collaboratively written "Raleigh Statement" led us to the principles and practices outlined below and also shone a light on the space for a guidebook such as this. Our hope is that this text will be used, useful, adapted, and the beginning of a deepening sense of the opportunities that libraries have to shape, develop, produce, and care for new forms of public knowledge as works of experiential scholarship.

The Immersive Scholar projects referred to are viewable at immersivescholar.org. Below are brief descriptions of each piece for the readers' context and information:

Coded Glass is a series of digital stained glass windows of protest signs, emojis, and hashtags from the \#metoo movement as a form of data visualization and metaphor for creating communal sacred spaces. The windows can be experienced online or in person at NC State's James B. Hunt Jr. Library in the iPearl Immersion Theater.

Community Gardens is an interactive data-driven generative art installation that uses gardens as a metaphor to discuss food and housing insecurity based on data from the NC State University student body. 
Community Gardens is online, and displays in circulation on Hunt Library's large scale visualization walls.

Tess-Celestial explores the interplay of art, nature, culture, shape, perspective, and math in our everyday lives. Created using the software Tess and KnotPlot, these tessellations show symmetries of hyperbolic, negatively curved space and convey the beauty and subtlety of mathematical concepts that we encounter in our daily activities. Tess-Celestial is on display at NC State, and can be viewed online.

Surface Tension is a visualization that maps streamflow data from the United States Geological Survey (USGS) in real time across the US, highlighting humanity's fraught relationship with fresh water. The map is currently on display at Hunt Library, and also online.

\section{Notes}

1. Hugh Denard, "A New Introduction to the London Charter," London Charter for the Computer-Based Visualization of Cultural Heritage, February 2009. http://www.londoncharter .org/.

2. Dave Hansen, Liz Milewicz, Paolo Mangiafico, Will Shaw, Mattia Begali, and V. McGurrin, A Framework for Library Support of Expansive Digital Publishing, A Framework for Library Support of Expansive Digital Publishing, 2008. https://doi.org/10.21428/68 $\mathrm{of}_{3353}$.

3. Beth Fischer and Hannah L. Jacobs, Visualizing Objects, Places, and Spaces: A Digital Project Handbook, Wired! Digital Art History \& Visual Culture. Accessed October 13, 2020. https://handbook.pubpub.org/. 
Throughout 2019-2020, Immersive Scholar had a number of fruitful conversations and interactions with colleagues working on the Virtual Martin Luther King Jr. (vMLK) Project. The goal was to look for shared approaches and challenges between experiential scholarship projects while harnessing the perspective of those entering from the side of research and scholarship rather than librarianship. The Reflection essays throughout this guidebook present those perspectives from Cynthia Rosenfeld and Abigail Feldman, representing two different disciplines, observing the interplay between Immersive Scholar and $v M L K$, offering both further food for thought and a lens into how faculty and students who are engaged in such projects might conceptualize them.

\title{
What Is an Aesthetic of Access?
}

\author{
ABIGAIL FELDMAN
}

D ocumentation, dissemination, and publication of experiential scholarship are forms of communication meant to reach a range of audiences and participants through a series of touchpoints over time. Experiential scholarship can be effectively communicated through a time and medium tailored to the needs and values of the specific audience. This situated transference requires designing. Rachel Clarke describes this quality of design as service, a responsibility of both librarians and designers that requires an empathetic understanding of situation and context to be able to identify the underlying needs of users. ${ }^{1}$ The tailored understanding of situation and context that manifests in the presentation and appearance of experiential scholarship communications for specific audiences is what I refer to as an "aesthetic of access." An aesthetic of access is not a singular mode, medium, or look, but a framework that directs attention to the affordances of mediums, the values and variability of participants, and the possibilities of continuous iteration. An aesthetic of access is what may help the significant properties of an experiential scholarship project be clearly distilled and conveyed to intersect with the needs of participants. ${ }^{2}$ It is through the frame- 
work of an aesthetic of accessibility that I extrapolate the principles laid forth in this guidebook.

\section{Notes}

1. Rachel I. Clarke, "Toward a Design Epistemology for Librarianship," The Library Quarterly, 88, no. 1 (2018): 41-59.

2. Significant properties are the components of a project that are critical to its intellectual and technical goals. I encountered the concept first in Module A4 of the Socio-Technical Sustainability Roadmap as characteristics to prioritize for project sustainability. Visual Media Workshop at the University of Pittsburgh, "Module A4: What Are the Project's Priorities?" The Socio-Technical Sustainability Roadmap. Retrieved June 17, 2020. https://sites.haa.pitt .edu/sustainabilityroadmap/a4-priorities/. 


\title{
A Rhetorical Framework of Disruption, Recovery, and Care
}

\author{
CYNTHIA ROSENFELD
}

$\square$ ach rhetorical insight essay in this guidebook approaches the principles and their practical applications through a framework of disruption, recovery, and care. Here, we take a moment to introduce this framework before applying it to the principles that follow.

Disruption refers to an affirmative disruption that views the interference in "the humanities associated with the development of new technologies as an opportunity to affirmatively rethink the human, the digital, and the humanities." 'We understand experiential scholarship to extend beyond the humanities and to include data and information visualizations and other aspects of digital scholarship more commonly associated with the sciences. We are not interested in putting, as some scholars suggest, a scientific gloss on the humanities or a humanistic gloss on the sciences. ${ }^{2}$ We are interested in how experiential scholarship invites us to understand the interactions and explore the fluid boundaries of the human and the digital, the humanities and the sciences. When we discuss experiential scholarship as recovery work, we are talking about how experiential scholarship practices can be oriented to social justice and work to "bring forth the full humanity of marginalized peoples through the use of digital platforms and tools." ${ }^{3}$ Care comes from a feminist ethic of care that we see taken up in work like that of the information maintainers and refers to the careful practices necessarily involved in experiential scholarship: sustaining and maintaining a project as acts of care, contributorship recognition as an act of care, and community interaction and dialogue as acts of care. Care is not understood as a one-size-fits-all model or a checklist with boxes to be ticked but as contextual, interrelated practices and responsibilities that will vary project by project. Finally, here, 
when we say we are offering insights on disruption, recovery, and care from a rhetorical perspective, we mean we are attending to the ways in which the principles of this guidebook orient librarians, scholars, and practitioners toward attitudes of reflection and engagement.

\section{Notes}

1. Janneke Adema and Gary Hall, "Posthumanities: The Dark Side of 'The Dark Side of the Digital,'” Journal of Electronic Publishing 19, no. 2 (October 1, 2016). https://doi.org/10.3998 /3336451.0019.201.

2. See, e.g., Timothy Brennan "The Digital-Humanities Bust.” The Chronicle of Higher Education 15 (2017).

3. Kim Gallon, "Making a Case for the Black Digital Humanities," in Debates in the Digital Humanities (Minneapolis: University of Minnesota Press, 2016). https://dhdebates.gc.cuny .edu/read/untitled/section/fa1oe2e1-oc3d-4519-a958-d823aac989eb. 


\section{Credit}

\section{Principle}

\footnotetext{
C ollaborative experiential scholarship projects should provide proper attribution to each individual involved in production of the work, in a manner that benefits their professional and personal status. ${ }^{1}$
}

\section{In Practice}

At the outset of the project, collaborators should openly discuss what is the most useful form of "credit" for their participation, which may not always be named attribution on a public website or co-authorship on a formal publication.

When listing collaborators in a public forum (website, co-author list, acknowledgments, etc.), honoring the wishes of participants that wish to be named, the project should employ an authoritative standard vocabulary that is human and machine readable. Early in the process:

- Decide and assign contributor roles

- Thoroughly document the contributor roles in many places: ${ }^{2}$

- project files

- public documents

- technical documentation

- final published product (book, website, articles, monograph, visualization exhibit, performance, etc.)

\section{Case Study from Immersive Scholar}

Inspired by discussions in the broad open science world around contributorship as an emerging form of attribution, and also the challenges of invisible 


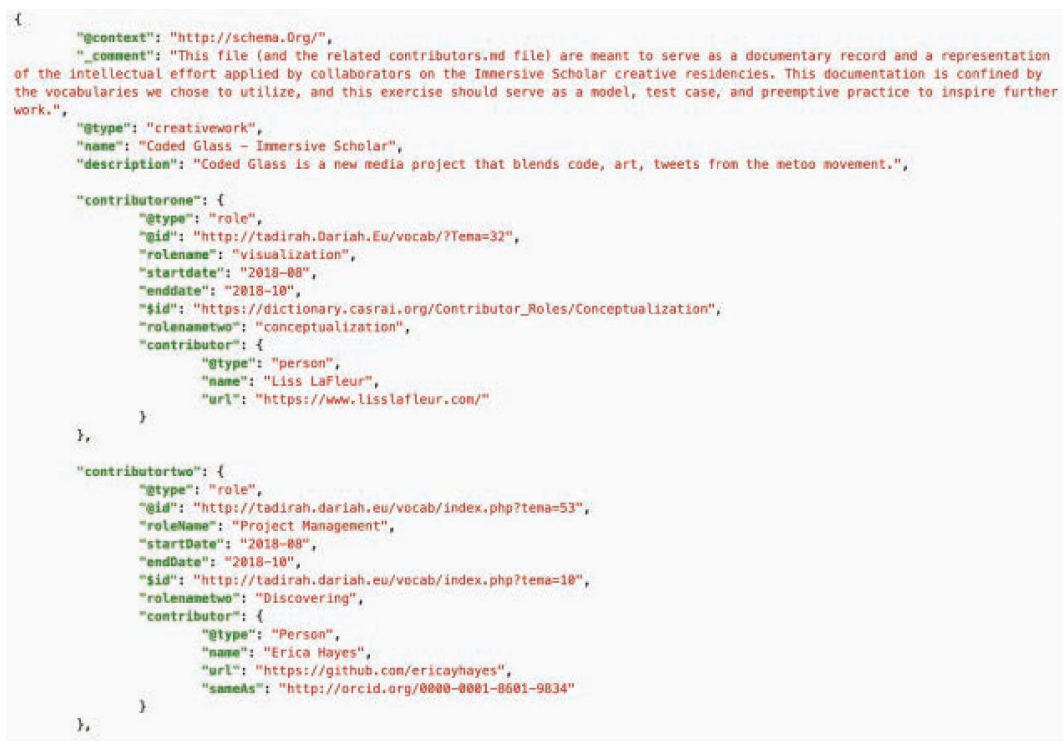

Sample code block of the Immersive Scholar Contributorship Data Model

labor in the digital humanities, the Immersive Scholar team at North Carolina State University drafted an exploratory contributorship methodology and data model. ${ }^{3}$

We applied the methodology to the Coded Glass visualization project first, primarily because it was the broadest set of roles and participants. The lead principal investigator Micah Vandegrift stuck sticky notes to a wall with each contributor's name, reviewed project notes and outputs to refresh how each person played a role, referenced the Contributor Roles Taxonomy (CRediT) and Taxonomy of Digital Research Activities in the Humanities (TaDiRAH), and assigned one term from each taxonomy as additional sticky notes to each person. Subsequently, Micah met with Jacob Shelby, NC State University Libraries Lead Metadata Technologies librarian, and after whiteboard brainstorming, together they drafted a JSON file that captured the following details for each person:

- Role-utilizing term name from the taxonomy, i.e., "outreach"

- Role ID—referencing the URI for the taxonomic term

- Start date of the specific role

- End date of the specific role 
- Contributor first and last name for the person who filled this role

- Contributor URL - referencing either a URL or ORCID for the person who filled this role

Following the completion of all our creative residencies, Micah and Erica Hayes, who served as the project manager through the residencies, along with research assistant Abigail Mann, who was involved in larger discussions about contributorship, met to retroactively assess and assign contributorship roles to Community Gardens, the second creative residency project we conducted. As is so often the case (and as we advise against above), we sought to parcel out contributorship after the project was completed. We utilized the same method as above, with the addition of a discussion around each person's activity and the best approximation of role descriptions from our chosen taxonomy to capture their work on Community Gardens. The result of both of these activities was a project-specific markdown file using a sentence to describe what each person did as well as a JSON file supporting those descriptions as a data layer. All of these files are available in the Immersive Scholar documentation hub. ${ }^{4}$

\section{Discussion}

Both of these taxonomies had some "holes" in terms of the work people had actually done on the project. In particular, issues like troubleshooting and training were tasks we frequently applied to contributors that didn't seem to have good analogs. We also found that a lot of contributorship seemed to clump at early stages - conceptualization/defining and sharing/disseminating. Strikingly, much of the literature that has emerged about these standards has pointed out the opposite problem: that late-stage activities such as editorship and review are also apt to be left outside of the contributorship possibilities. ${ }^{5}$ It might be fair to say that much of the developed language of contributorship still focuses narrowly on the production of "a document" rather than the broad constellation of scholarly activities and outputs that can be seen as transforming the very universe of scholarly communications. ${ }^{6}$

In particular, we noted that CRediT is aimed very much at the articleas-only-product model, within the context of hard science. There is no real space for post-publications, alternate media, or social dissemination, all forms that an experiential scholarship project may embrace to reach out to alternate audiences and communities. Indeed, we noted in the process that 
we used the taxonomic term "writing" very broadly here to define any sort of communication. TaDiRAH does offer multiple forms of explaining dissemination and what it terms "meta-activities," so it works well for communication to the public but offers more difficulty in assigning planning roles such as gathering information or defining issues.

\section{What You Can Learn from Us}

- It may well be helpful to consult various taxonomies as you begin to see what best fits the project at hand.

- Think in both directions. What roles describe the people involved in the project? What roles described might be necessary to the project but need a person who can fulfill that role?

- Recognize that existing contributorship taxonomies often efface the early and end stages of a project.

- To counteract that effacement, roles can be further explained in the human readable version and people in the community can continue to advocate for further additions and clarifications. ${ }^{\text {? }}$

All of the above rest upon a model of visible, assigned contributorship. Not every contributor may want credit; some may seek other forms of agency within the project and this should be a foundational discussion with all participants. ${ }^{8}$

\section{Several Key Themes Emerge from the Relevant Literature}

This section synthesizes the key points of a number of critical discussions. Because it focuses on foundational claims in the texts, we do not offer particular quotations or pagination; rather, this section offers a broad overview of some general consensus in the critical conversation.

\section{Why Do This?}

What value does better defining roles in the production and dissemination of scholarship hold? There is a spectrum of responses to this question. At the most practical level, not counting certain activities - like coding, visualization, and research design - means that there is no incentive for people to become expert in those activities, substantially holding up research activities. ${ }^{9}$ A slightly more global problem is one of communication. When contributorship roles are not clearly defined, valuable time is spent trying to explain or replicate certain crucial roles. ${ }^{10}$ As a general principle, not iden- 
tifying contributors beyond the author(s) obscures the transparency and openness of the research project-an ethical concern that becomes even more striking during a time when how research is done and disseminated is rapidly changing. ${ }^{.1}$

\section{Beyond the Author}

Many of the available taxonomies still imagine some sort of authorship or original conception as the primary form of valued contributorship. ${ }^{12}$ This can lead to continued blind spots in assigning technical, financial, and conceptual and editorial contributorship, among others. ${ }^{13}$ It also may hold back key elements of the research process, such as reproducing and replicating results, since those are not "authored" per se..$^{14}$

\section{But, Don't Get Lost in the Collaborative}

At the same time, it is important to recognize that there are forms of experiential scholarship that are truly single authored. Assigning credit for diverse roles should not put pressure on scholars to redistribute work that may be key to their development or to produce more quickly through a team what might be better conceived singly over a longer span of time. ${ }^{15}$

\section{Credit versus Participation}

One useful thought-experiment might be shifting away from the idea of "credit," be it in prestige or pay, as the sole way in which to acknowledge involvement. Much of this has to do with multiple ways in which agency might be understood. For the historian in a digital humanities project, for instance, the specific project might be the final goal, while for the digital scholarship center that hosts the project, the ability to reuse the code in other endeavors might be the key value. ${ }^{16}$ Shifting from the outcome of a research activity to the processes may help to reshape how the very concept of credit is imagined.

\section{Visible versus Invisible}

While one of the foundational goals of thinking about credit might be making invisible labor visible, it is important to remember that for some participants, visibility might not be desirable or helpful. ${ }^{17}$ Translators, editors, statisticians, and others who are paid for their contribution have no control over the final product and may not wish to be connected to it for various 
reasons. ${ }^{18}$ Rather than unproblematically assuming that visibility is the only form of valuation, it is important to stay aware of the situated forms of value.

\section{Practical Considerations}

While individual attributions of credit are important, it also remains true that the modes of dissemination and publishing hold a key role in opening up the forms of attribution accepted or sought and defining these expectations for the contributor. ${ }^{19}$ Submitters can help create an environment for this, though, by submitting such attributions and actively asking for inclusion in editorial policies. ${ }^{20}$

\section{Resources We Found Particularly Useful in Forming These Ideas ${ }^{21}$}

Bourne, Phil, T. Clark, R. Dale, A. de Waard, I. Herman, E. Hovy, and D. Shotton (eds., on behalf of the Force11 community) (2011). Force11 White Paper: Improving the Future of Research Communication and e-Scholarship. October 27, 2011. http://force11.org/. Copyright 2011.

Graban, Tarez Samra, P. Marty, A. Romano, and M. Vandegrift. "Introduction: Questioning Collaboration, Labor, and Visibility in Digital Humanities Research." Digital Humanities Quarterly 13, no. 2 (2019): np.

Holcombe, Alex. "Farewell Authors, Hello Contributors." Nature 571 (2019): 147. https://doi.org/10.1038/d41586-019-02084-8.

Matarese, Valerie, and Karen Shashok. "Transparent Attribution of Contributions to Research: Aligning Guidelines to Real-Life Practices." Publications 7, no. 2 (2019): article 24. https://doi.org/10.3390/publications7020024. 


\section{Reflections}

\section{Contributorship - Abigail Feldman}

An aesthetic of access can further the aims of contributorship by attending to participants' stake in their experiential scholarship. Stake, in this case, refers to both the form participants' contributions take and to the participants' values, needs, and goals in relation to the experiential scholarship. To recognize their qualitative stake in relation to experiential scholarship through contributorship requires privileging the contributors' relationship with experiential scholarship over singular, specific tasks or behaviors. ${ }^{22} \mathrm{As}$ both participants and their relationships to an experiential scholarship project vary, so should the form contributorship takes. If contributorship should meet the needs and values of contributors, the logical way to identify those qualities is through direct conversation with the participants. It is with a deeper understanding of their perception of their relationship to the work that relevant forms of acknowledgment can be imagined.

An experiential scholarship project can be conceived of as a web of knowledge. The knowledge that is directly presented to an audience through some experiential medium is perhaps the most obvious, but who the contributors are, and what they have done in relation to the project is another form of knowledge. This latter type of knowledge has the potential to make use of the affordances of nontraditional and new mediums in the same way more obvious experiential knowledge does. Perhaps it may be difficult to reimagine the form of contributorship because of its inherent connection (as a credit-giving label) to authorship. Authorship as an identification is itself intimately connected to form. In the most traditional context, an author is the figure that receives credit for a text. A text can be many things, but in the same traditional context, it is likely a written work. Prior to the digital realm, written work needed to be printed in order to be read and disseminated. Including the name of the author on the printed work had the practical benefit of being a form of attribution that is readily available to readers who may only come in contact with the printed form. Authorship played well to the affordances of print, and though scholarship now exists in the digital and beyond, authorship has been retained as a familiar researcher reward structure. In the same vein, contributorship is a structure that seeks 
to play to the affordances of the new forms of knowledge created through experiential scholarship.

Experiential scholarship knowledge can be mediated through innumerable kinds of technology. Much of that technology has the potential to be instantaneously connected. Regardless of what the exact technology is, this interconnectivity allows for contributorship that is intentionally layered. If experiential scholarship may now be considered a less traditional text, added layers of contributorship may be considered paratext. ${ }^{23}$ In contemporary technology, a few possible forms of paratext regarding contributorship could include audio, haptics, a video overlay, or a linked document. ${ }^{24}$ Ideas for what paratext may contain may be drawn from Angel David Nieves's description of deep annotations: "annotations with more information than is traditionally practiced to include primary and secondary source materials accessible through a robust digital archive and through lengthy supporting historical text or another kind of narrative layer." ${ }^{25}$ An interconnected technology system is one method of approaching contributorship in a new way, but the notion of paratextual practices should not be linked to technology. They should be utilized toward the essence of contributorship: imagining meaningful possibilities for those who have been involved, are presently involved, and will be involved.

Applying an aesthetic of access to contributorship also considers how contributors are situated in time. Looking at contributorship over time necessitates an understanding of experiential scholarship projects as a series of evolving manifestations rather than a beginning, middle, and end. It requires recognizing those who perform the work of maintenance, preservation, transition, and the sources that have informed and influenced the conception of the project as contributors. The Virtual Martin Luther King (vMLK) Project is a work of experiential scholarship that pays close attention to the ways in which the past has informed the project through a technology of recovery framework. ${ }^{26}$ vMLK involved the congregation of White Rock Baptist Church as partners in the re-creation of Martin Luther King Jr.'s speech "A Creative Protest." Congregation members were present during the recreation and are heard in the virtual MLK project documentary. The congregation were contributors not only in the re-creation, but their participation in the original speech of Dr. Martin Luther King contributed to the conceptualization of the vMLK project itself. The contributorship of the congregation is explicitly called out in the VMLK project documentary and on the website. 
These specific callouts make it possible for the vMLK project to additionally recognize contributorship in action. The involvement of the present-day congregation as a means of acknowledging the involvement of the past congregation in the original speech is action as contributorship. vMLK's action as contributorship is a practice that further stretches the conversation around what contributorship can be.

\section{Disruption, Recovery, and Care:}

\section{Contributorship-Cynthia Rosenfeld}

When considering contributorship, the disruption, recovery, and care framework directs our attention to issues of recognition and attribution, as well as responsibility and accountability. Disrupting the idea of authorship is not new to experiential scholarship. In 1967, literary critic Roland Barthes proclaimed "the death of the author" and emphasized that (a) authorship is never individual but is drawn from innumerable cultural interactions, and (b) how the text lives with its audience has primacy over the author's intentions. ${ }^{27}$ Experiential scholarship - as an emerging form of scholarship that is (often) necessarily collaborative - offers an opportune sphere in which to affirmatively rethink our practices of acknowledging contributorship in a way that is "collaboratively and responsibly built and shared." 28

A fuller accounting of contributorship as recommended in this guidebook makes visible, or recovers, the collaborators and acts of labor that may otherwise be marginalized. Paraphrasing actor Tom Hanks in A Beautiful Day in the Neighborhood, we must ask ourselves, "Who are all the people who loved this project into being?" In Coded Glass, Katelyn Hudson, Anthony Fuqua, and Eduardo Miranda - each of whom work in artist Liss LaFleur's studio - are named and their roles are described. This stands in contrast to a vaguer acknowledgment that might have concealed those contributions by attributing work to "Liss LaFleur and designers from her studio." Rather than a "thank you" screen that provides a list of names with unknown contributions, we learn, for instance, that Jacob Shelby used his expertise to help the team develop their metadata schema and modeling for contributorship.

In experiential scholarship, we can experiment with how we display or orient audiences to contributorship. In the 2020 video documentary of the Virtual Martin Luther King Project, viewers not only see the names of contributors but hear from the contributors and the many perspectives they bring to the project. The 2020 vMLK documentary video is also a significant 
example because it is not the first version of the video. The 2020 video adds three minutes of footage and a plurality of previously unheard voices. Whereas the previous documentary concluded with credits that include special thanks to the people of White Rock Baptist Church and the James B. Hunt Jr. Library, the 2020 documentary reveals those contributions by letting the members of the church and contributors from the library speak to their experience..$^{29}$ Iterative, collaborative projects contain vast networks of contributors who come and go throughout the project's life cycle. Of course, every act of recognition reveals a thread of a larger network that has not been unraveled. There is something tempting about a line that acknowledges Hunt Library without naming individuals because the recognition of "Hunt Library" gestures toward all the individuals, technologies, and infrastructure of the actor-networks that make a project possible. ${ }^{30}$

Creative and meaningful acknowledgment of contributorship needs to be on the radar from the earliest stages of project development. Here, we can see the entangled and interdependent relationship between contributorship and documentation and why both principles are foundational to ethical practices of experiential scholarship. Caring for experiential scholarship projects and the labors that create and maintain them necessitates that we stay with the trouble, attend with care, embrace the messiness, and make visible the ongoing nature of contributorship.

\section{Notes}

1. Tarez Samra Graban et al. argue that "equal partnerships rely less on equal credit and more on an open communication of goals and on an understanding of cash vs. cache - that is, an understanding that equality may be determined not in precisely the same outcomes for each participant, but each participant should still have access to what they need, whether that is in financial compensation (cash) or in project stakes (cache). Put simply, there are types of credit that are often overlooked in a too-rigid framework of credit equals pay or prestige. It might be more important to have ongoing responsibility for a work, or rights to modify a work, than to have public visibility about one's past contribution or to have continued ownership of it." Graban et al., "Introduction: Questioning Collaboration, Labor, and Visibility in Digital Humanities Research," Digital Humanities Quarterly 13, no. 2 (2019): para 18. Valerie Matarese and Karen Shashok added that "emerging evidence from surveys of professional authors' editors and translators shows that many (especially those working in disciplines other than the life sciences) do not consider acknowledgment necessary or even desirable, for a variety of reasons. Because they lack control over the manuscript after they complete 
their work (i.e., they lack "last-look rights"), many editors and translators are concerned that changes made after their input has ended will not be representative of the quality of their own contributions. Additionally, because acknowledgment may be seen as an endorsement of the conclusions, they may prefer not to have their name associated with the publication." Valerie Matarese and Karen Shashok, "Transparent Attribution of Contributions to Research: Aligning Guidelines to Real-Life Practices,” Publications 7, no. 2 (2019): article 24. https://doi. org/10.3390/publications7020024.

2. The Force11 White Paper notes that while the internet "opens up opportunities for new processes that can accelerate the growth of knowledge, including the creation of new means of communicating that knowledge among researchers and within the wider community ... research processes and the dissemination of research results have yet to fully assimilate the capabilities of the web and other digital media. Producers and consumers remain wedded to formats developed in the era of print publication, and the reward systems for researchers remain tied to those delivery mechanisms." Phil Bourne et al., eds., Force11 White Paper: Improving the Future of Research Communication and e-Scholarship, October 27, 2011. http://force11.org/.

3. Graban et al. note that "the problem of invisibility is at its core a problem of validation, where the goal of visibility exists principally to make it easier to validate the internal work of the Digital Humanities participants." Graban et al., "Introduction," para 10.

4. Visit the Immersive Scholar documentation hub at https://osf.io/3z7k5/wiki/Contri bution\%2omethodology/.

5. Matarese and Shashok argue that CRediT conflates editing and peer review and the stages of drafting in a way that currently "make it difficult or impossible to accurately and transparently identify the sometimes substantial contributions of those who work with authors." Matarese and Shashok, "Transparent Attribution," np.

6. The Force11 White Paper, in addition to defining the many new modes of disseminating research, notes that "to obtain the benefits that networked knowledge promises, we have to put in place reward systems that encourage scholars and researchers to participate and contribute. We need to acknowledge the fact that notions such as journal impact factor are poor surrogates for measuring the true impact of scholarship, and are increasingly irrelevant in a world of disaggregated knowledge units of vastly varying granularity; and we need to derive new mechanisms that allow us more accurately to measure true contributions to the ongoing enterprise of augmenting the world's store of knowledge." Bourne et al., Force11 White Paper, np.

7. Matarese and Shashok, for instance, suggest a series of additional categories and clarifications of different roles. Matarese and Shashok, "Transparent Attribution," np.

8. Graban et al., "Introduction"; Matarese and Shashok, "Transparent Attribution."

9. Alex Holcombe, "Farewell Authors, Hello Contributors," Nature 571 (2019): 147. https:// doi.org/10.1038/d41586-019-02084-8.

10. Graban et al., "Introduction."

11. Bourne et al., Force11 White Paper.

12. Matarese and Shashok, "Transparent Attribution."

13. Graban et al., "Introduction"; Matarese and Shashok, "Transparent Attribution."

14. Holcombe, "Farewell Authors, Hello Contributors."

15. Graban et al., "Introduction." 
16. Graban et al., "Introduction."

17. Graban et al., "Introduction."

18. Matarese and Shashok, "Transparent Attribution."

19. Bourne et al., Force11 White Paper.

2o. Holcombe, "Farewell Authors, Hello Contributors"; Matarese and Shashok, "Transparent Attribution."

21. Further resources can be found at https://www.zotero.org/micahvandegrift/items /collectionKey/3FBG49EC.

22. Care is not a single duty or task, but an ethic that is carried out over time, in relation to something. An ethic of care in information maintenance is developed in Information Maintenance as a Practice of Care: An Invitation to Reflect and Share. This white paper makes the call for highlighting forms of information maintenance that can be defined by relationships to one another. The Maintainers, Information Maintenance as a Practice of Care: An Invitation to Reflect and Share, Information Maintainers. Retrieved June 17, 2019. https://themaintainers .org/info-mc-work.

23. Paratext includes all the material that surrounds an initial text.

24. Possible forms referenced from Nadine Desrochers, ed., Examining Paratextual Theory and Its Applications in Digital Culture (Hershey: IGI Global, 2014).

25. Angel D. Nieves, "Developing a Social Justice Framework for Immersive Technologies in the Digital Humanities," Keynote for the Immersive Pedagogy Symposium, Pittsburgh: Carnegie Mellon University, 2019.

26. Kim Gallon, "Making a Case for the Black Digital Humanities," in Debates in the Digital Humanities (Minneapolis: University of Minnesota Press, 2016). https://dhdebates.gc.cuny .edu/read/untitled/section/fa1oe2e1-oc3d-4519-a958-d823aac989eb.

27. Roland Barthes, “The Death of the Author." Contributions in Philosophy 83 (2001): 3-8.

28. Andrea E. Pia, Simon Batterbury, Agnieszka Joniak-Lüthi, Marcel LaFlamme, Gerda Wielander, Filippo M. Zerilli, Melissa Nolas, et al., "Labour of Love: An Open Access Manifesto for Freedom, Integrity, and Creativity in the Humanities and Interpretive Social Sciences," Commonplace, July 16, 2020. https://doi.org/10.21428/6ffd8432.a7503356.

29. This discussion of how contributorship models display contributions and who and what gets revealed and concealed was influenced by Lawrence J. Prelli, ed., Rhetorics of Display (Columbia: University of South Carolina Press, 2006).

30. For more on actor-networks, see Bruno Latour, Reassembling the Social: An Introduction to Actor-Network Theory (Oxford: Oxford University Press, 2007). 


\section{Decouple}

\section{Principle}
xperiential scholarship works are multitudinous and should be built and distributed in multiple forms not only to increase access and ac- cessibility, lower technical barriers, and broaden the reach of the work but also to invite and appeal to different audiences.

\section{In Practice}

Project planning involves identifying different "significant properties" for different audiences and recognizing that the unifying unit of the work is less about the final product(s), and more about the interlinks between them all. ${ }^{1}$ This underscores the value and necessity for interoperability in metadata about research artifacts and researchers.

Some possible outputs that may be decoupled and distributed broadly are:

- Code

- Data

- Visual assets

- Executable files

- Lesson plans

- Book chapters

- Project documentation

- Exhibition materials

- Journal articles

- Software packages

- Images

- Audio files 


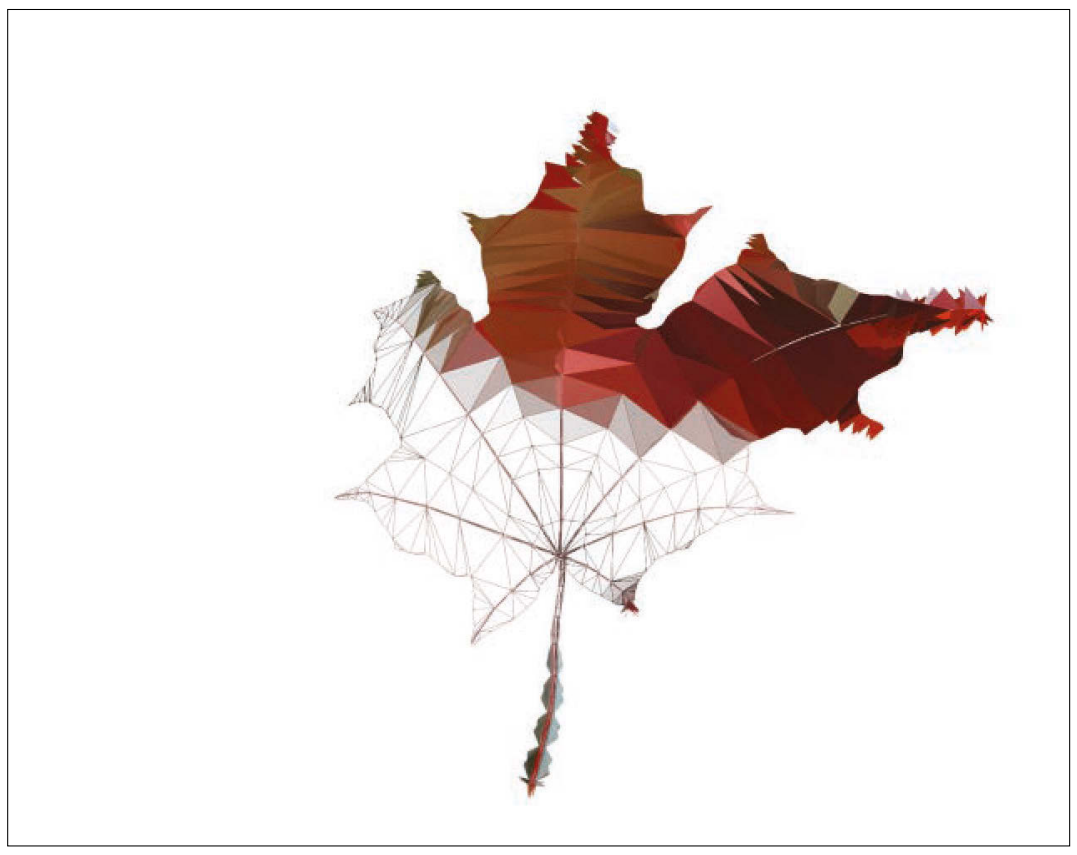

Generative art leaf from Lucas Swick's Community Gardens

\section{Case Study from Immersive Scholar}

Throughout the creative residencies of Immersive Scholar, we attempted various parts of a decoupled approach. In the case of Tess-Celestial, we separated the workstreams of the visualization project and the research project, understanding that each stream, while connected, would result in a different output with disconnected audiences. Similarly, in the construction of Coded Glass we replicated the content of the project across three different spaces online: codedglass.com, ImmersiveScholar.org, and the Open Science Framework Immersive Scholar repository. This was facilitated by the fact that we worked with residents who were comfortable creating, managing, and maintaining their own web products. A final strategy enacted at the close of the grant project is the capture and distribution of .warc (web archive) files of each project website, as well as video captures of their live display, to be deposited in a general repository (e.g., Humanities Commons, Zenodo) for increased discovery.

At a meta-project level, decoupling was foundational to the decision 
that each project we developed would be delivered online in addition to the in-person experience available on campus at North Carolina State University. More deeply, in deploying a three-layered strategy for the web, we borrowed a digital preservation emphasis on multiple "copies" stored in multiple places: our website (immersivescholar.org) is the access point, the Open Science Framework (OSF) repository is the documentation hub, and a collection in Conifer, a high fidelity web archiving tool, is the "preservation" copy of the various sites and assets around the project. While not exact replications, each site mirrors and points to the others as an interconnected web of primary source outputs.

Practically, this meant the lead principal investigator and project manager for Immersive Scholar invested regular time in strategizing best methods and options for capture, description, and deposit of the project assets and maintenance of links and pointers to the decoupled and distributed files. Full enactment of this principle across our project included an inventory of affiliated material, strategizing the constellation of possible virtual homes for them, portioning them across the sites/repositories, linking and connecting them to a documentation hub, and revisiting the workflow as necessary.

\section{Discussion}

The idea of transmedia, or communicating ideas through multiple genres, has surfaced in multiple fields in recent years. ${ }^{2}$ In applying this concept to experiential scholarship, we draw heavily upon Colin Anderson and Stéphane McLachlan's division of three key ways in which the "knowledge transfer paradigm," wherein "knowledge is transferred from knowledge 'producers" to knowledge 'users," can be successfully transformed to a public endeavor: transmedia itself, layering, and building bridges. ${ }^{3}$ We adopt these three mobilization strategies as a useful starting place in thinking about decoupling results from both the traditional academic monograph and the idea that a single communication suffices to share an idea.

In employing layering, as outlined in our case study, the project website should serve as a hub, with the project assets distributed as spokes on a wheel, rather than each and all fully integrated into the site itself. Starting from the assumption of different audiences, identifying the best and most appropriate access point for them becomes a fundamental action from the outset. ${ }^{4}$ This is akin to what a scientific research lab would do in planning the 
spread of their research papers from a single project across various journals for maximum impact and to reach certain segments of the field.

Experiential scholarship relies intensively on many humans from many disciplines collaborating to produce a work of public and scholarly engagement. While different stakeholders in the project benefit from different formats, there still must be "bridges": common terms, images, metaphors, examples, or objects that serve as shared frames of reference and allow users to move from asset to asset as they need. ${ }^{5}$ Early on, a project manager or leader should seek to identify and document several key bridges and urge contributors to use them, as well as updating and communicating changes as they organically emerge.

One common theme arose in reflecting on each of these principles but perhaps most vividly in discussing decoupling: "I wish I had known then what I know now." If experiential scholarship relies upon transmedia, it is inarguable that when researchers bring in a complement of technical skills, both planning and execution are easier. This can be seen in the Community Gardens Immersive Scholar project, in which the researcher's facility in digital creation and project management made it much easier to conceptualize and execute a layered project with multiple audiences, hubs, and outputs. Yet it is important to note that researchers with a less diverse array of skills were, with support, able to build projects that reached new audiences in new ways through multiple nodes. ${ }^{6}$

We might conclude then that while experiential scholarship requires a steep learning curve and intensive support, it is open to a broad variety of researchers and should be embarked upon for the needs of knowledge diffusion rather than because of the skill set of the knowledge producer. What certainly can be done consciously is centralizing the issues of decoupling the work and planning needed to successfully reach audiences. Through the course of the residencies and a collaborative exchange in the summer of 2020 with our colleagues in the Virtual Martin Luther King Jr. Project, we identified themes of "participatory readiness" and challenges of working with/in transmedia as similar across our two projects, reifying that the more support offered up front, the better.

Yet even in an imaginary world in which every researcher has every technical skill, experiential scholarship projects would still require a certain amount of "future casting" in terms of long-term preservation. Decoupling knowledge diffusion from the traditional academic monograph means that 
multiple digital artifacts will be produced. Two major issues in terms of planning for preservation surfaced throughout the Immersive Scholar projects. What can we do to pre-prepare for possible preservation (without having that commitment secured yet), and how can we pre-solve the sustainability questions that should always be asked at the outset of a project but never actually are? We attempted to create a decoupled framework that utilized existing infrastructures rather than creating new buckets and thus new sustainability challenges. Our hope is that this then allows a public exhibition of the project to meet different needs and use cases than can a research article, or a pedagogical activity.

\section{What You Can Learn from Us}

- Establishing the transmedia nature of the project from the start and identifying early on the various modes in which knowledge diffusion should happen for a particular audience allows the project manager to connect researchers with resources and tutorials as needed.

- Discussion of the practical aspects of digital curation, including ingest, preservation actions, and storage have to be early and regular. Long-term access and stability must be planned and monitored.

- While we did not explicitly identify "bridges” for projects, having common terms, images, metaphors, examples, and objects that serve as shared frames of reference and allow users to move from asset to asset speaks to many of the goals of experiential scholarship, so in the future, we would build in bridge discussions earlier in the process.

In each of the above bullets, the project manager has a vital role in creating participatory readiness and maintaining meaningful output. This guidebook assumes that, because of their position and charge, that project manager is often the librarian. Librarians, then, are intermediaries who serve not only to host the technological tools or output of experiential scholarship, but also to act in an almost editorial role, helping to identify main themes and stakeholders and suggesting tools and approaches to achieve those goals. This is a new role and requires careful negotiation, but since the librarian may, through working with multiple experiential scholarship projects, end up with the most wide-ranging sense of what experiential scholarship can do and to whom it speaks, they can be crucial in this intermediary role. 


\section{Several Key Themes Emerge from the Relevant Literature}

This section synthesizes the key points of a number of critical discussions. Because it focuses on foundational claims in the texts, we do not offer particular quotations or pagination: rather, this section offers a broad overview of some general consensus in the critical conversation.

\section{What Makes Up a Communication?}

Academic writing is frequently understood as a process of knowledge transfer from "producers" - academics - to "users" - practitioners, government and industry, and sometimes the public, although they are perceived as less informed and engaged. ${ }^{7}$ However, fundamental to any form of communication is recognition of the many components that make it up, both physical and cultural. Physically, elements such as visualizations, front matter, mode of publication, and modes of access - some controlled by the researcher and some controlled by other actors - all shape how a reader can encounter and understand a communication. ${ }^{8}$ Ideologically, expectations that academic communications are unbiased and neutral and can be reported in discrete intervals linked to academic advancement shape both what and how traditional academic communications can be shared. ${ }^{9}$

\section{Shifting Modes of Communication in Academia}

Disciplines from the humanities to the social sciences to the natural sciences have all, in recent years, examined the value of transmedia approaches in academic communications as a means to add in marginalized voices, explore other viewpoints, and demonstrate new patterns and solutions. Transmedia approaches employ multiple platforms, with each individual text offering specific and meaningful elements. ${ }^{10}$ In addition to transmedia approaches, building bridges, by identifying and regularly using key words, ideas, and examples, and layering, or creating texts that employ different levels of details for different audiences, also offer alternatives ways to think about communicating research. ${ }^{11}$

\section{Technological and Ideological Pressures}

The explosion of media and software, from social media to visualizations, videos, soundtracks, hypertexts, and game applications have all shaped thinking about communication. ${ }^{12}$ Financial and practical considerations 
allowed changes in both the speed and flexibility in publication options. ${ }^{13}$ At the same time, academia has increasingly recognized the ways in which a model predicated on objectivity excludes many actors. Multiple theorists suggest that an increasing focus on interactive and transmedia allows more nuance, more participation across wider audiences, more engagement, more impact, or more bibliodiversity. ${ }^{14}$ An emphasis on "cognitive justice" demands both that communications mobilize knowledge as much as possible and that such communications involve citizens beyond academics. ${ }^{15}$

\section{Effects on Audience}

A fundamental claim about transmedia approaches is that they allow the opportunity to reach more audiences in more ways. Transmedia modes focus on active engagement rather than passive absorption. ${ }^{16}$ Additional elements can allow alternative interpretations and meanings, ones that may contradict or complicate each other but that ultimately may lead to different ways of knowing. ${ }^{17}$ Including the voices of the traditionally disenfranchised can lead to greater engagement, understanding, and action, and destabilization of traditional power structures. ${ }^{18}$

\section{Creators beyond Authors}

Ultimately, transmedia approaches decenter the idea of a singular author: there is no one singular voice, mode, or conclusion. ${ }^{19}$ Using multiple modes means that writers, designers, and other contributors can all be seen as "authors" who are in dialogue with each other as they develop elements of the whole. ${ }^{20}$ The same holds true of readers who also become active makers of meaning as they navigate between different forms of communication. Rather than the researcher dictating meaning, readers make sense across platforms, leading, perhaps, to greater participation in the debates themselves. ${ }^{21}$

\section{Resources We Found Particularly Useful in Forming These Ideas}

Anderson, Colin, and Stéphane McLachlan. "Transformative Research as Knowledge Mobilization: Transmedia, Bridges, and Layers." Action Research 14, no. 3 (2016): 295-317.

Hancox, Donna. "From Subject to Collaborator: Transmedia Storytelling and Social Research." Convergence 23 no. 1 (2017): 49-6o.

Genette, Gerard. Paratexts: Thresholds of Interpretation. Trans. J. E. Lewin (Cambridge: Cambridge University Press, 1997). 


\section{0 | IMMERSIVE SCHOLAR}

Jenkins, Henry. Transmedia Storytelling (Cambridge: MIT Review, 2003). http:// www.technologyreview.com/news/401760/transmedia-storytelling/. Accessed April 2, 2020.

McLellan, Hilary. "Digital Storytelling in Higher Education." Computing in Higher Education 19 (2007): 65-79. https://doi.org/10.1007/BF03033420.

Sadokierski, Zoë. "From Paratext to Primary Text." LOGOS: The Journal of the World Book Community 27 no. 1 (2016): 22-30. https://doi org.libproxy.lib.unc .edu/10.1163/1878-4712-11112095.

Shearer, Kathleen, Leslie Chan, Iryna Kuchma, and Pierre Mounier. "Fostering Bibliodiversity in Scholarly Communications: A Call for Action." Zenodo (2020): np. http://doi.org/10.5281/zenodo.3752923. 


\section{Reflections}

\section{Decoupling - Abigail Feldman}

"Decoupling" implies the separation of connected parts. In the context of experiential scholarship, these connected parts are forms of media. Each media is simultaneously an independent experience and an entrance to the broader ecosystem of an experiential scholarship project.

That ecosystem contains all the media through which the experiential scholarship can be experienced, but it is given form as a cohesive whole by the relationships that connect the media. These relationships are inclusive of the significant properties of an experiential scholarship project and are open to the possibility of further development. Experiential scholarship should be conceived as a network of information that is decoupled in delivery rather than as a form of technology. Scholars may then prioritize what experiential scholarship can do through various forms of technology rather than what it can solely be as technology.

In this case, "doing" broadly refers to the systemic impact of an experiential scholarship network. An aesthetic of access calls for attention to the intersection of this systemic impact, and the values and needs of potential participants. In this context, what an experiential scholarship project does can be reinterpreted as what it does for participants. The focus of scholars thus shifts to consider who the project is reaching, who it still could reach, and where adequate space exists for the knowledge ecosystem to grow.

In accordance with the "Raleigh Statement on Good Practices for Developing Experiential Scholarship Projects," decoupling in practice points toward distributing experiential scholarship through different media such as virtually (online), physically in an immersive space, and narratively in the form of a text, video, or presentation. Beyond volume of media, an aesthetic of access can be actively engaged in the practice of decoupling by considering what the affordances of the media are, and how those affordances help knowledge reach relevant audiences. For example, André Brock describes Twitter as an example of immediacy afforded Black discourses by network protocol, communal structures, instantaneity, and archival capacity of information networks. ${ }^{22}$ Knowing this, an experiential scholarship project that intends to engage Black discourses should consider Twitter as one of the media to best reach this audience, based on its alignment with their values. 
The vMLK project uses a decoupled approach with six different components - historical experience, collective sound experience, listening experience, virtual reality experience, simulation experience, and share your creative protest - that can be uniquely configured in multiple ways for both physical and digital spaces through public performances, walking tours, virtual reality tours, and online exhibitions. vMLK also works with institutions to develop a unique format to fit their specific needs. Beyond volume, vMLK considers how the information network is made active with media through the technology of recovery framework. One of the primary themes of this framework is that technologies of recovery innovate the use of digital tools to consider how studying Black history reveals the methodological constraints and possibilities of digital technologies, and the ways Black studies "may come to bear on and transform the digital processes and tools used to study humanity." In this context vMLK acts as a case study in which it highlights the strengths and weaknesses of digital technologies in providing immersive transmedia experiences for this purpose. ${ }^{23}$ Through this framework, vMLK considers the affordances of the media used in the project while simultaneously questioning why a medium may lack affordances for its audience.

When decoupling an experiential scholarship project, scholars should keep in mind what the knowledge system does for its audience and apply an aesthetic of access to intentionally choose media that will enhance its ability to do so.

\section{Disruption, Recovery, and Care:}

\section{Decouple-Cynthia Rosenfeld}

If someone were to read chapter 2 on decoupling without reading chapter 1 on contributorship, it would be understandable if that person came away from the chapter overwhelmed, confused, and perhaps a bit frustrated. The affirmative disruption (see "A Rhetorical Framework of Disruption, Recovery, and (are") of decoupling and digital work may sound like a disconfirming disruption to one's expertise and area of practice. Like Gunnar Nygren's study, "Multiskilling in the Newsroom - De-skilling or Re-skilling of Journalist Work?," decoupling without collaboration could sound like an unrelenting, unforgiving task that asks scholars to go miles wide and to somehow find time to become proficient in multiple media development software and languages. ${ }^{24}$ So, it is worth taking a moment to reiterate that the work of 
decoupling takes place in a community of collaborators and contributors, and no one person (or project, even) is expected to produce all of the possible outputs we have suggested. Librarians are crucial collaborators in the work of decoupling. Librarians can help scholars think through the types of outputs possible with their project ideas and share resources for the development of those projects.

With that preface, there is good reason to be excited about the possibilities afforded by decoupling. Decoupling can help "bring forth the full humanity of marginalized peoples through the use of digital platforms and tools" by offering more routes of access for engagement with different publics. ${ }^{25}$ Further, decoupling "makes room for multiple points of access and for literacies of participation may begin to make academic research more transferable and usable." ${ }^{26}$ Decoupling is at the heart of the experimental and experiential work of Immersive Scholar. Immersive Scholar's Surface Tension video was displayed on walls at Hunt Library, video can be accessed on personal computers via the artists' website, and open source code from the project is available on GitHub. The Virtual Martin Luther King (vMLK) Project - a partner with Immersive Scholar but not an Immersive Scholar project - has put together a "kit of parts," a digital handbook that explicates the contributions of each of the exhibit's components and offers an ability for exhibitors to tailor the experience as best suited for their community.

In Steven Johnson's (2011) Where Good Ideas Come From, he discusses how innovation begets innovation. One act of innovation opens a door to a room with many more doors, as each innovation makes new things possible. Johnson refers to this as the "adjacent possible." 27 Decoupling helps us explore the adjacent possibilities, and it does something else, too. Instead of thinking about how a project like Surface Tension opens a door to a room with many more possibilities, think of the reverse: Decoupling means there are many doors that open to the space of Surface Tension. By offering many paths of access, we make it easier for more publics to locate and engage our projects and to have found their way there through a passageway that has meaning for them.

When we recover something, we find or retrieve something that was lost, stolen, or taken away. By offering multiple modes of engagement and varied points of access, the work of decoupling can help people retrieve the lost, stolen, and taken away stories of people who have been marginalized. In 
rhetoric, we might say that decoupling is an act of addressing multiple rhetorical situations - that is, understanding the needs of multiple publics and making use of the constraints of different media to produce a "fitting" output of the project - simultaneously. ${ }^{28}$ Another way of saying it is that decoupling is a way of caring for peoples and projects. Decoupling is a careful and affirmative intervention into the hegemonic digital record.

\section{Notes}

1. Anderson and McLachlan suggest that there are three key ways in which the "knowledge transfer paradigm" in which "knowledge is transferred from knowledge 'producers" to knowledge 'users' ... who are ... perceived as deficient in scientific understanding" can be successfully transformed to a public endeavor. They draw out "three key knowledge mobilization strategies: using transmedia to exchange knowledge across a range of communication media; building bridges to invite communication amongst diverse knowledge communities; and layering to communicate knowledge at varying levels of detail. These strategies can be used in any knowledge mobilization program to maximize the potential for progressive social transformation." We adopt these three mobilization strategies as a useful starting place in thinking about decoupling results from both the traditional academic monograph and from the idea that a single communication suffices to share an idea. Colin Anderson and Stéphane McLachlan, “Transformative Research as Knowledge Mobilization: Transmedia, Bridges, and Layers.” Action Research 14, no. 3 (2016): 296-297. See https://sites.haa.pitt.edu /sustainabilityroadmap/a4-priorities/.

2. Henry Jenkins's description of transmedia as that which "unfolds across multiple media platforms with each new text making a distinctive and valuable contribution to the whole" has been foundational to many theorists. Henry Jenkins, Transmedia Storytelling (Cambridge: MIT Review, 2003), 50. http://www.technologyreview.com/news/401760 /transmedia-storytelling/.

3. Anderson and McLachlan draw out "three key knowledge mobilization strategies: using transmedia to exchange knowledge across a range of communication media; building bridges to invite communication amongst diverse knowledge communities; and layering to communicate knowledge at varying levels of detail. These strategies can be used in any knowledge mobilization program to maximize the potential for progressive social transformation." replace with Anderson and McLachlan, "Transformative Research," 296-297.

4. Anderson and McLachlan argue that using layers "recognizes that the complexity, length, and technical language of most academic writing exclude many actors from the processes of knowledge mobilization. Layering involves strategically determining the level of detail, complexity, and language required to effectively communicate ideas and arguments with different types of actors (e.g., professional academics, farmers, policy makers, or the general public). However, layering does not endorse a hierarchy of knowledge based on an a priori 
assumption that scientific writing and communication is more valuable than applied and reality-grounded approaches. Rather, the question that should determine value, and indeed should create a new hierarchy of knowledge, is: to what use can this knowledge (complex or simple) be used, through processes of social transformation, to create a more just and sustainable world. Our cross-linking of these high-impact pieces with the long-form and technical versions generated opportunities for actors to move back and forth among these layers to access a wider diversity of information as needed." Anderson and McLachlan, "Transformative Research," 306-307.

5. Anderson and McLachlan suggest that an attention to bridges stems from the "recog[nition] that different knowledge mobilizers are separated by epistemological, discursive, and disciplinary divides. In order to work across these boundaries, it is necessary to employ key words, examples, metaphors, objects, and discourses that can create bridges between those with different politics, sensibilities, and interests. The use of bridges is especially important for marginalized actors whose ideas are often sidelined by more powerful discourses.... While boundary objects act to maintain, 'coherence across intersecting social worlds' (Star and Griesemer, 1989, 393), these bridges are more experimental and less durable. Instead, bridges serve to catalyze moments of transgression and may (or may not) evolve into more durable boundary objects. Like boundary objects, however, these bridges can draw together actors from different social worlds to prompt new insight, innovation, knowledge, and products (Carlile, 2002)." Anderson and McLachlan, “Transformative Research," 307.

6. It is important to think about these audiences in terms of diversity and equity. Donna Hancox observes "an emerging intersection between the affordances of digital technologies and the recognition of the stories of marginalized people," opening the opportunity for "transmedia storytelling to create projects that are able to offer a multiplicity of voices and to create stories that can represent complex issues without privileging a particular point of view or story form." Donna Hancox, "From Subject to Collaborator: Transmedia Storytelling and Social Research." Convergence 23 no. 1 (2017): 49.

7. Anderson and McLachlan, "Transformative Research."

8. Hancox, "From Subject to Collaborator"; Gerard Genette, Paratexts: Thresholds of Interpretation, translated by J. E. Lewin (Cambridge: Cambridge University Press, 1997); Zoë Sadokierski, "From Paratext to Primary Text," LOGOS: The Journal of the World Book Community 27 no. 1 (2016): 22-30. https:// doi org.libproxy.lib.unc.edu/10.1163/1878-4712-11112095.

9. Anderson and McLachlan, "Transformative Research."

10. Anderson and McLachlan, "Transformative Research”; Hancox, "From Subject to Collaborator”; Jenkins, Transmedia Storytelling; Hilary McLellan, "Digital Storytelling in Higher Education," Computing in Higher Education 19 (2007): 65-79. https://doi.org/10.1007/BFo3033420.

11. Anderson and McLachlan, "Transformative Research."

12. McLellan, "Digital Storytelling in Higher Education"; Sadokierski, "From Paratext to Primary Text."

13. Hancox, "From Subject to Collaborator"; Sadokierski, "From Paratext to Primary Text." 14. Anderson and McLachlan, "Transformative Research"; Hancox, "From Subject to Collaborator"; Kathleen Shearer et al., "Fostering Bibliodiversity in Scholarly Communications: A Call for Action,” Zenodo (2020). http://doi.org/10.5281/zenodo.3752923. 
15. Anderson and McLachlan, "Transformative Research."

16. McLellan, "Digital Storytelling in Higher Education."

17. Anderson and McLachlan, "Transformative Research"; Hancox, "From Subject to Collaborator"; Sadokierski, "From Paratext to Primary Text."

18. Anderson and McLachlan, "Transformative Research"; Hancox, "From Subject to Collaborator."

19. Hancox, "From Subject to Collaborator."

20. Hancox, "From Subject to Collaborator"; Sadokierski, "From Paratext to Primary Text."

21. Hancox, "From Subject to Collaborator."

22. André Brock, “Theorizing Black Technoculture,” AAD Hum Intentionally Digital, Intentionally Black Conference (College Park: University of Maryland, 2018).

23. This description of the work of vMLK comes from Victoria Gallagher, one of the project's principle investigators.

24. Gunnar Nygren, "Multiskilling in the Newsroom: De-skilling or Re-skilling of Journalistic Work?” The Journal of Media Innovations 1, no. 2 (2014): 75-96.

25. Kim Gallon, "Making a Case for the Black Digital Humanities," in Debates in the Digital Humanities. Debates in the Digital Humanities 2. (Minneapolis: University of Minnesota Press, 2016). https://dhdebates.gc.cuny.edu/read/untitled/section/fa1oe2e1-oc3d-4519-a958 -d823aac989eb.

26. Alyssa Arbuckle and Bonnie Stewart, "How Can We Make Scholarship More Relevant?" Inside Higher Ed (blog), November 13, 2017. https://www.insidehighered.com/blogs/university -venus/how-can-we-make-scholarship-more-relevant.

27. Steven Johnson, Where Good Ideas Come From: The Natural History of Innovation (New York: Riverhead Books, 2011).

28. Lloyd F. Bitzer, “The Rhetorical Situation," Philosophy and Rhetoric 25 (1968/1992): $1-14$. 


\section{Document}

\section{Principle}

ecause works of experiential scholarship are wide and diffuse, the doc-
umentary impulse should be employed rigorously and approached as
a primary research output of the project.

\section{In Practice}

- Establish a "documentation hub" and decide which forms of documentation will be public and which are for the internal team.

- Recognize that each research group, individual collaborator, and team will bring their own norms to a project.

- To convert practice to praxis, charge a translator/gatherer with the primary responsibility of documenting the process of the project. The impulse to add this task to the project manager should be avoided; the project manager's role is momentum while the documentor's is capture. ${ }^{1}$

- Broadly define documentation. Don't just focus on "welldocumented code."

- Have a good documentation strategy for the decoupled project assets with realistic tactics and assigned responsibility. ${ }^{2}$

\section{Case Study from Immersive Scholar}

The Immersive Scholar project team invested in documentation as a primary and central aspect of the project due in part to a long history we inherited from the digital humanities and library project management literature. The choice to utilize the Open Science Framework as a public hub for the project 

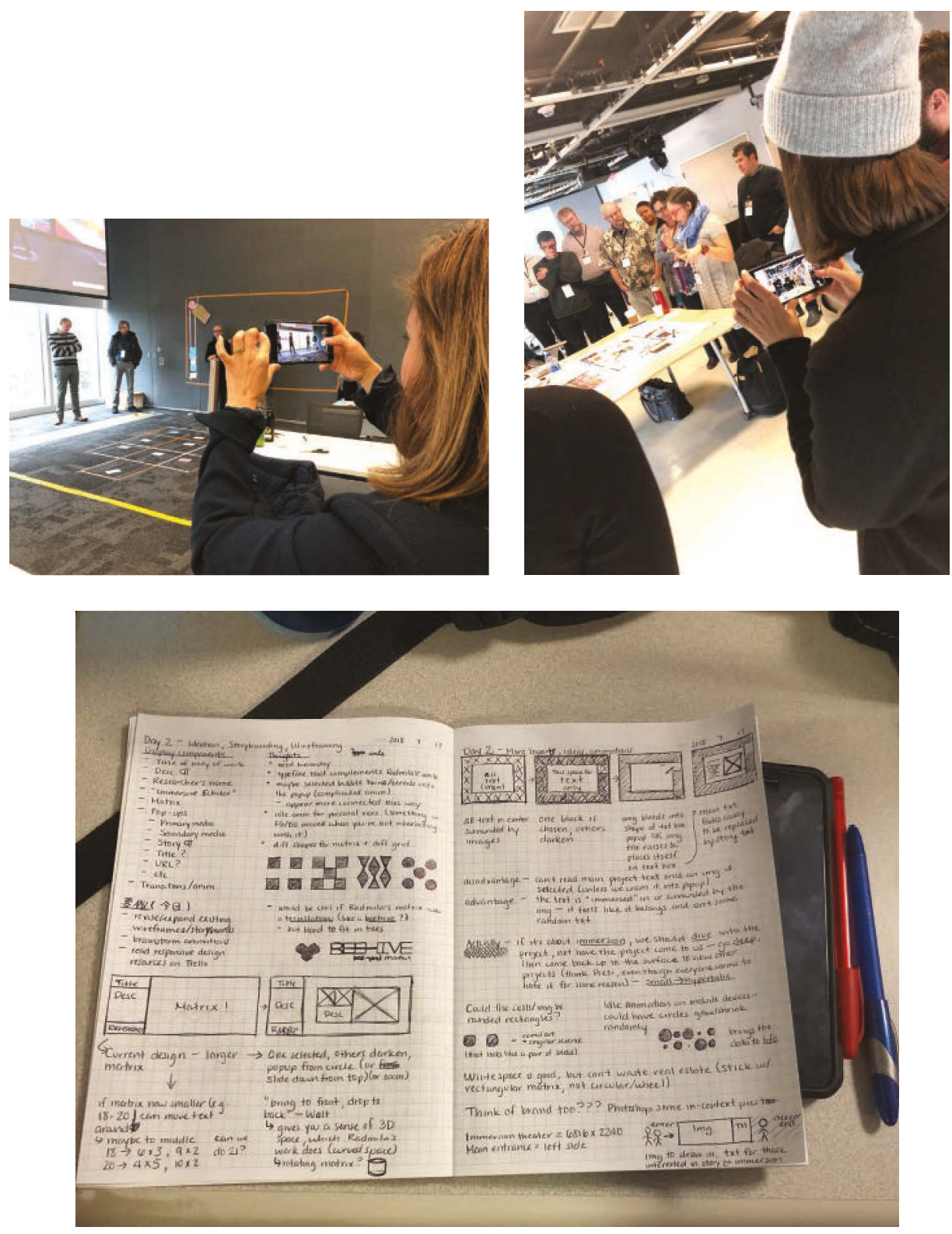

Documenting the planning, presentation, and production of Immersive Scholar projects. Photographs by Micah Vandegrift 
documentation solidified our decision by offering several key features: an integrated wiki, component projects, the ability to plug other tools into the hub (Zotero, GitHub, Box), the ability to list contributors, light file storage, and the option to mint a DOI. We also set up an Immersive Scholar GitHub organization to fork the repositories of our project partners and provide static site hosting for the experiential works that we manage and maintain.

We employed a documentation strategy at three specific levels: (1) for the whole Immersive Scholar project, (2) specifically for North Carolina State University Library's portion of the project, and (3) for each creative residency. Specific examples of each are below:

- The Immersive Scholar Project: The top-level Open Science Framework project is a behind-the-scenes (but not internal) glimpse of the various project partners, an abstract about the grant and project work in the wiki, and a map through the various components and files that the project depended on.

- The North Carolina State University Libraries component project describes our contributions as individuals, our preservation tactics for the project outputs, and summaries and links to the activities we undertook, including hosting the creative residencies.

- The residency component projects provide the following documentation from each project: code, data, and content (stills, media, narrative, etc.). Interestingly, each creative resident did so in similar, but unique ways. Liss LaFleur compiled a finely designed narrative document that was loaded into the OSF file storage for her project, Lucas Swick built documentation into the project website, which also serves as the visualization's display medium, and Caitlin and Misha compiled an extensive README document in their project's GitHub that is integrated into the Immersive Scholar GitHub organization.

In addition to project documentation, we were particularly inspired by our colleagues from the University of Pittsburgh's Visual Media Workshop's SocioTechnical Roadmap for Project Sustainability, and their explication of the differences and utility of documenting the content, context, and structure. ${ }^{3}$ We utilized Rhizome's Conifer tool alongside the OSF wiki to document Immersive Scholar content of the creative projects displayed online, context in the articles, presentations, and press about the works, and finally the structure in the data, technical dependencies, and narrative description of the creative works. 
Overall, documentation of the Immersive Scholar project is deep-spanning from sharing the grant project's high-level goals down to describing the project development processes we employed — and wide — distributed across various platforms and sites like our project website, Open Science Framework and Conifer for contextual information, and finally various repositories for the scholarly outputs of the projects.

\section{Discussion}

Documentation as a practice for digital projects is ill-defined. The definition we developed, inspired by our colleagues at Duke University and their Wired! Lab's Handbook for Digital Projects, is:

Narrative and/or graphical descriptions of process, decisions, labor, and the results of intermediate parts of a project. Documentation can include things like: a contributor's file, sitemap, .warc file (web archive), project readme, recommended citation, project asset index, graphical workflows, and more. Documentation can also be a primary published artifact of the project. $^{4}$

Our case studies suggest that while most people document, everyone has a different vision of what good documentation is and where it should reside. ${ }^{5}$ As we suggest, it is helpful to appoint a translator/gatherer of documentation who can focus on the particulars. Admittedly, this creates a certain amount of replicated labor, but creating a standardized documentation that all contributors must use may lead to a loss of some fine-grained detail and perhaps even interesting insights about how the contributor anticipates documentation being used and by whom. ${ }^{6}$

At the same time, of course, expectations must be set from the beginning since documentation can be very hard to muster retroactively. ${ }^{7}$ Simply the fact that documentation needs were built into the terms of the residencies may well have built an awareness and sensitivity to documentation into the actions of the researchers. It is also important that documentation occurs at all levels, as it did here. ${ }^{8}$ While a set form is not necessary, an effective methodology to communicate expectations, capture robust data, and nurture shared values of documentation is. ${ }^{9}$ While the project manager should not be the documenter, they can most certainly be the "documentation cheerleader." 
Finally, the interoperability of various documentation tools makes a significant difference in what gets documented and how. At a basic level this means choosing or designing a hub carefully, with meticulous attention to the ways in which others with similar projects may have chosen to document their work. ${ }^{10}$ It also means that hosting choices may shape documentation choices. With our choice to use the OSF hub, did the availability of Zotero suggest the importance of a library of background material? Did the availability of Box lead to the idea that larger files and texts could serve as part of the documentation?

\section{What You Can Learn from Us}

In writing these case studies and reflections, we found that we were less focused on what we could do differently in the future or what didn't work. Documentation was baked into this project from the start, and as a result, the practice allowed us to see how it could work effectively in experiential scholarship. This highlights the importance of intentionality in documentation particularly, but in all of these principles more generally.

One major factor in this emphasis was that Micah Vandegrift served in the "documentation coordinator" role on each of these projects. While not directly involved in the execution of particular projects, he was cognizant of the larger goals and projects of Immersive Scholar and each residency. This is the ideal positioning of a documentation translator/gatherer, although of course resources will dictate who can play this role and how much time they can commit.

One trend that became clear both in discussing documentation and reading the literature is that documentation is becoming ever more necessary and luckily, more valued as well. Buy-in is easier to achieve and if we were to future cast, we might say that documentation will become an expected element in any discussion around scholarly communication. ${ }^{11}$

\section{Several Key Themes Emerge from the Relevant Literature}

This section synthesizes the key points of a number of critical discussions. Because it focuses on foundational claims in the texts, we do not offer particular quotations or pagination: rather, this section offers a broad overview of some general consensus in the critical conversation. 


\section{Sustainability}

At the technical level, sustainability in digital projects is about preservation of data and metadata. ${ }^{12}$ Yet it is also about institutional concerns: the continuation of activities and services of the organization and the sustained viability to users. ${ }^{13}$ Digital preservation is assumed to have a relatively short life span, meaning plans for sustaining materials must be consciously made in a way not necessary for a monograph or traditional works of art. ${ }^{14}$

\section{Audience Needs}

It is important to consider the accessibility of the location in which documentation is stored, especially when thinking about how an object may travel outside of institutional bounds. ${ }^{15}$ In addition, various levels of documentation-high-level summaries, focused examples of functions, contributors versus users versus other stakeholders, experienced versus novice - can be generated, and it is important for both creators and users to be cognizant of different possible uses. ${ }^{16}$

\section{Moving beyond the Book}

Traditionally in academia, the finished product has been equated with a book, monograph, or essay. The problem with this is it assumes a static final product, while many experiential works may evolve over time. ${ }^{17}$ By contrast, in the art world, there is a resistance to the impulse to catalog and fix; for many artists, art is in a constant state of change and development. ${ }^{18}$ It is, however, worth thinking about documentation as something that becomes stable over time in terms of discoverability, authority, and sustainability. ${ }^{19}$

\section{Tools for Further Exploration}

The idea of "tactical reuse" shapes the importance of documentation as much as the data collected, the services, tools, and approaches developed by a project may be of key interest to others in the field. ${ }^{20}$ From the creative side, this imagines a new approach to artistic productions in which "we want to make software and methods something more dialogical, less precious, more open, more viral."21 This is a common practice in software, in which Open Source Software libraries allow programmers to import the code to execute specific functions. ${ }^{22}$ This idea of reuse opens up who can work with data since technical skills do not necessarily need to be at a high level.This 
capability highlights the need for accurate and helpful documentation. ${ }^{23}$ Additionally, it allows institutions to create persuasive arguments about future investments for stakeholders. ${ }^{24}$

\section{Resources We Found Particularly Helpful in Forming These Ideas}

Chassanoff, Alexandra, and Colin Post. OSSArcFlow Guide to Documenting BornDigital Archival Workflows. Educopia Institute. June 23, 2020. Accessed August 18, 2020. https://educopia.org/ossarcflow-guide/.

Edmond, Jennifer, and Francesca Morselli. "Sustainability of Digital Humanities Projects as a Publication and Documentation Challenge." Journal of Documentation 76, no. 5 (2020): ahead-of-print. https://doi.org/10.1108/JD-12-2019-0232.

Fostano, Katherina, and Laura K. Morreale. "The Digital Documentation Process.” The Digital Documentation Process. January 31, 2019. Accessed September 16, 2020. https://digitalhumanitiesddp.com/.

Geiger, R. Stuart, Nelle Varoquaux, Charlotte Mazel-Cabasse, and Chris Holdgraf. "The Types, Roles, and Practices of Documentation in Data Analytics Open Source Software Libraries." Computer Supported Coop Work 27 (2018): 767-802. https://doi.org/10.1007/s10606-018-9333-1.

Koeser, Rebecca Sutton. “Document ALL the Things!” Center for Digital Humanities@Princeton University.August 12, 2019. https://cdh.princeton.edu/updates /2019/o8/12/document-all-things/.

Lozano-Hemmer, Rafael. "Best Practices for Conservation of Media Art." September 28, 2015. https://github.com/antimodular/Best-practices-for-conservation -of-media-art.

Steeves, Vicky. “Investigating and Archiving the Scholarly Git Experience." IASGE. November 5, 2018. https://investigating-archiving-git.gitlab.io/about/.

Visual Media Workshop at the University of Pittsburgh. "Module A5: Project Documentation Checklist." The Socio-Technical Sustainability Roadmap. Accessed June 17, 2020. https://sites.haa.pitt.edu/sustainabilityroadmap/a5 -documentationchecklist/. 


\section{Reflections}

Workflow Transparency: DocumentationAbigail Feldman

The practice of documentation is not new, but it does take on different appearances depending on both the type of media and the field it comes from. For example, the documentation of a public performance, a virtual simulation, and an audio experience would look different; yet all three could be outputs of a single experiential scholarship project. What can the documentation of scholarship that is created through the convergence of different media and disciplines look like?

Guidelines for uniform technical documentation of components of experiential scholarship exist under the Testing Guidelines for Immersive Digital Applications (see appendix) drafted by Walt Gurley as a part of the work of Immersive Scholar. As a researcher encountering these ideas for the first time, I wonder: if an experiential scholarship project is more than technical components, how can documentation capture the significant properties that link those components to create a holistic body of work? Answering this question begs another: what and who is this kind of documentation for? In artist Rafael Lozano-Hemmer's piece Subtitled Work, you enter an empty room, are tracked by computerized surveillance, and a random verb is projected on your body that follows you everywhere. The only way to get rid of the word is to touch somebody and exchange words with him or her. The project was written in Delphi, using firewire cameras, IR illuminators, and XGA projectors. Lozano-Hemmer's documentation of the project covers the technical functioning and also includes a migration workflow for the project to function with different technologies. The purpose of this, in LozanoHemmer's words, is "because this particular project is not about the specific tracking and projection used but about the experience of words branding the public." ${ }^{25}$ In the case of Subtitled Work, words branding the public are the significant properties that tie the two different versions together. It is what the project is "doing."

Documenting migration is a practical way of documenting an experiential scholarship project's nontechnical significant properties because it highlights what is transferable beyond the technology. Migration can be as explicit as Lozano-Hemmer's plans for a version that operates on entirely different technology, but it can also exist through the documentation of 
the microchanges that illuminate a project's evolution over time. To ensure these changes are captured, they should be documented in tandem with the development of the project from its inception. The GitHub data folder of the Immersive Scholar project Surface Tension documents microchanges made over the course of the project with file names like "renaming surfacewater to streamflow because that's more accurate in terms of what this is, which is a subset of surfacewater." These names give those encountering this documentation insight as to why changes were made, and what is significant to the project.

Documentation toward migration reinforces the conception of experiential scholarship as an ecosystem of parts that can grow and change. Participants who may extend or influence the bounds of an experiential scholarship project answer the question of who the documentation is for. Those participants can include a breadth of audiences with varying intentions. In the case of vMLK, a few of those audiences could be teachers, students, scholars, and publics. If those groups were interested in extending vMLK in some way, they would likely find different forms of documentation useful for doing so. While documentation should have a universal language directed toward the widest possible audience, additional pathways with relevant information could serve the needs of different audiences. Students who participated in the vMLK project through COM 110, an introductory foundational course for public speaking skills at NC State University, documented their own experience in writing. They addressed their learning experience, perception of the project, and the accessibility of assets, which was then compiled in a summary report. This is an artifact that could be included in a vMLK documentation pathway meant for teachers and students.

An aesthetic of access in documentation is foregrounded in the idea that experiential scholarship is a living system. Documentation of a living project is therefore responsible not only for preservation but also for providing a framework open to possibilities for various future interlopers.

Disruption, Recovery, and Care:

Workflow Transparency-Cynthia Rosenfeld

Documentation can be quite tricky. Each experiential scholarship project has many elements to document, primary among them: (1) contributorship, (2) process of creation or method, and (3) a record of assets. I would like to take a quick detour from scholarship into entertainment to help us think about documentation in creative and careful ways. 
Recently, my partner and I were watching a stand-up comedy special on Netflix. Toward the end of the show, the comic tells a story, and in that bit, the comic's father gets a good punchline. Upon hearing the punchline, my partner proclaimed, "He stole that. That is a famous [comedian] line." Indeed, it is so famous that Googling just three key words from the twosentence joke immediately brings up the other comedian. At least one reviewer of the special pointed to the usage and its origins and suggested the prior comedian was owed royalties. I went back to the special and watched the credits to see if there was any kind of acknowledgment or attribution, and there was not. I began to wonder how the comedian could have documented the source of the joke. Certainly, I would not have wanted the verbal equivalent of a parenthetical note to rupture the flow of his narrative. Yet, the lack of any acknowledgment in the credits was unsatisfying, and I became curious about the process of invention itself. Perhaps he truly believed that was his father's witticism. Alternatively, as the joke originated from a comedian known to be - literally - violently opposed to joke theft, perhaps the present comedian included the unattributed joke as a critique on comedic authorship.

Though this is not an essay about joke theft and documentary practices, the performance did provide a kairotic - or opportune-moment to reflect on documentation practices and ask questions:

- How do we document the process and practices of invention and maintenance, and where and how should that documentation be shared?

- What processes do we currently understand as warranting documentation, and what practices would we ideally like to see documented? For example, we may provide a "suite of tools" listing in our production notes, but are we capturing the public(s) engagement in our documentation?

- What audiences need documentation, and what kinds of documentation do those different audiences need?

- How do we document contributorship (chapter 1) in decoupled (chapter 2) projects in ways that provide meaningful attribution but are not jarring to an experience?

- How do we engage in transparent documentation of the process of invention, creation, and maintenance that avoids the pitfalls of becoming (a) an unsustainable addition to a team's labor, (b) information overload that pollutes rather than illuminates, and (c) read as prescriptive? 
The above questions get at the issues of recovery and care that are foundational to the work of documentation. Science fiction writer Arthur C. Clarke claimed that, "Any sufficiently advanced technology is indistinguishable from magic." ${ }^{26}$ One might certainly find exploring the beautiful, virtual summer and winter gardens representing food and housing (in)security at NC State a magical experience, both in its beautiful artistry and its powerful symbolic action, but it would be unfortunate if other scholars explored Community Gardens and felt intimidated by the magic rather than inspired by the possibilities. One goal of documentation is to encourage other experiential scholarship projects by sharing tools and techniques. The documentation hub for Community Gardens reveals the complexity of the project and the elegance of its execution, while also making the process of invention visible.

\section{Notes}

1. Princeton's Center for Digital Humanities office, for instance, separates data curation work from research partnerships entirely. Katherina Fostano and Laura Morreale separate out "project leaders (researchers) who initiate digital project-work, and information scientists (cataloguers) who catalog the material created," although as we acknowledge, the librarian often takes on the project manager role. Katherina Fostano and Laura K. Morreale, "The Digital Documentation Process," January 31, 2019. Accessed September 16, 2020. https://digitalhumanitiesddp.com/.

2. Fostano and Morreale suggest three outputs: a catalogue record, a persistent identifier, and an archiving dossier narrative. Fostano and Morreale, "The Digital Documentation Process," np. While Lozano-Hemmer is aiming his advice at artists, he offers some good general guidelines: while creating, "keep a notebook and/or electronic document where you put any sketches, prototypes, parts lists, bits of research on the project; use open source tools as much as possible; consider using versioning systems, like Git. These allow your software projects to be traceable incrementally and they are a great repository for fundamental information on how a project evolves; backup software; prepare a 'Bill of materials' (BoM), which is basically a list of all components of a piece. List each separate component, writing its brand and model, its function, the URL for information, and a small picture for each, name it as replaceable or irreplaceable for the work as a whole; as much as possible, use off the shelf or global choices in components and hardware. After making, consider the following: make a video of the project, ideally with you speaking over it and explaining proper functioning; install on a variety of computers to test for any issues with software or hardware and document in a "Read Me" to be bundled with all installers; prepare one or several flash drives with all the source code for your project, including firmware, binaries, media assets, schematics, $3 \mathrm{D}$ print files, EVERYTHING..... These flash drives are meant to be like a time capsule that hold all the instructions required to reproduce the work; write a manual with the following parts: i) a 
'meta' narrative describing the key concepts and elements of the piece and how it works; ii) a detailed set-up procedure, including pictures of example installations, wiring diagrams, museographic notes such as desired lighting or acoustic conditions, sample layouts showing what is and is not allowed; iii) maintenance section on how to clean the piece and turn it on and off; iv) preservation section with the Bill of materials, all schematics, comments to the code." Rafael Lozano-Hemmer, "Best Practices for Conservation of Media Art from an Artists Perspective," 2015. Reprint, Antimodular Research, September 10, 2020, np. https://github.com /antimodular/Best-practices-for-conservation-of-media-art. Alexandra Chasanoff and Colin Post identify a number of communal documentation steps, including file identification and format characterization, creating an accession record and creating and extracting metadata, with suggestions for applicable tools for each step, as well as a questionnaire for everyone involved in a project. Alexandra Chassanoff and Colin Post, OSSArcFlow Guide to Documenting Born-Digital Archival Workflows, Educopia Institute, June 23, 2020. Accessed August 18, 2020. https://educopia.org/ossarcflow-guide/.

3. Visual Media Workshop at the University of Pittsburgh, "Module A5: Project Documentation Checklist," np.

4. As Jennifer Edmond and Francesca Morselli point out, the emphasis on documenting end products derives from an equation of the finished product with a book: "once complete, it is relatively stable and (within the normal expectations for environmental conditions) likely to be available and discoverable through a library for the long term." They point out that this "misses emerging recognition that much of the value of scholarship must be captured in its processes, not merely in its products." Jennifer Edmond and Francesca Morselli, "Sustainability of Digital Humanities Projects as a Publication and Documentation Challenge," Journal of Documentation 76, no. 5 (2020): 1019-1031, https://doi-org/10.1108/JD-12-2019-0232.

5. Lozano-Hemmer notes that from the creative rather than scholarly side, there can be a resistance to documentation: "we snub techniques that may help us document, organize or account for our work as something that stifles our experimentation and creative process." Lozano-Hemmer, "Best Practices for Conservation of Media Art," np. Geiger et al. report a finding that while almost $100 \%$ of programmers see incomplete documentation as a pervasive problem, $60 \%$ rarely or ever document. R. Stuart Geiger, Nelle Varoquaux, Charlotte MazelCabasse, and Chris Holdgraf, "The Types, Roles, and Practices of Documentation in Data Analytics Open Source Software Libraries," Computer Supported Coop Work 27 (2018): 769. https://doi.org/10.1007/s10606-018-9333-1. Thus, it becomes all the more crucial to make sure all contributors are invested in documentation from the start.

6. Geiger et al. note that "documentation work ... is often a mode of collective sensemaking about not just the specific task at hand, but how the task fits into the organization's broader goals and principles." Geiger et al., "The Types, Roles, and Practices of Documentation," 773. Chasanoff and Post add that "coming together (virtually or in person) to assess your workflows is a constructive exercise that will foster your shared awareness of the work currently being done and provide you with a space to build consensus around your future goals and priorities for born-digital archiving." Chassanoff and Post, OSSArcFlow Guide to Documenting Born-Digital, 31.

7. The Visual Media Workshop describes a communal storage site: "Although each re- 
searcher has their own data-collection and drafting processes, the team is making a concerted effort to apply a common strategy to its communal research documentation by using the concept of 'reliable sites.' Reliable sites of project documentation designate those locations that we agree are communally kept and community-essential, and they are therefore watched over by us all. We all also commit to keeping these locations filled with timely, reliable, and accurate information." They suggest keeping the number of locations small, keeping the folders simple (their top-level folders are generally articles/books/links, data, process documentation, and sites of production), backing up these sites, and separating out drafts and working documents and project management and communication information. Visual Media Workshop at the University of Pittsburgh, "Module A5: Project Documentation Checklist," np.

8. Geiger at al. note that "successful projects intentionally adopted a broad definition for what it meant to 'contribute to documentation'” but that defining types gave documentors a shared vocabulary and sense of purpose. Geiger et Al., "The Types, Roles, and Practices of Documentation," 778 .

9. Edmond and Morselli argue that the "sustainability" documentation works to achieve "must be underpinned not just by an understanding of 'what' and plan for 'how,' but by solid conceptions of 'why' and 'for whom." Edmond and Morselli, "Sustainability of Digital Humanities Projects," 1024. Lozano-Hemmer, speaking to an audience of artists, suggests that planning documentation from the start will "i) simplify our life in the long run, ii) generate income, and iii) take ownership of the way our work will be presented in the future." LozanoHemmer, "Best Practices for Conservation of Media Art," np.

10. Geiger et al. point to the hidden expectations of documentation created by community standards of various platforms, noting that "what constitutes good documentation is often contextual to various uses and goals, subjectively interpreted by different people, and left underspecified in community norms." Geiger et al., “The Types, Roles, and Practices of Documentation," 789 .

11. As Edmond and Morselli note, the problem of digital preservation "intersects with some of the key concerns of contemporary scholarly communications in the humanities: new forms of scholarly process and output are proliferating faster than systems can be built to recognise and preserve their contributions, and to meet for them the traditional aspects of scholarly publishing, such as dissemination, registration, archiving, and accreditation." Edmond and Morselli, "Sustainability of Digital Humanities Projects," 4-5. Lozano-Hemmer argues that on the creative side, instruction-based art, as far back as Duchamp, proves that a form of documentation "has been happening in the artworld for a hundred years." Lozano-Hemmer, "Best Practices for Conservation of Media Art," np. Fostano and Morreale argue that archiving dossier narratives, their outlined documentation text that "explain[s] the value of computer-enabled work" in a way that "enables fair evaluation ... by credit-granting bodies," ideally "would be published in field-specific journals, thereby bringing fellow researchers into the DH-inflected conversation." Fostano and Morreale. "The Digital Documentation Process," np.

12. Edmond and Morselli, "Sustainability of Digital Humanities Projects as a Publication and Documentation Challenge"; Geiger et al., "The Types, Roles, and Practices of Documentation"; Visual Media Workshop at the University of Pittsburgh, "Module A5: Project Documentation Checklist." 


\section{O | IMMERSIVE SCHOLAR}

13. Edmond and Morselli, "Sustainability of Digital Humanities Projects"; Geiger et al., "The Types, Roles, and Practices of Documentation”; Visual Media Workshop at the University of Pittsburgh, "Module A5: Project Documentation Checklist."

14. Edmond and Morselli, "Sustainability of Digital Humanities Projects"; Sutton Koeser, “Document ALL the Things!” Center for Digital Humanities@ Princeton University. August 12, 2019. https://cdh.princeton.edu/updates/2019/o8/12/document-all-things/; LozanoHemmer, "Best Practices for Conservation of Media Art"; Chassanoff and Post, OSSArcFlow Guide to Documenting Born-Digital Archival Workflows.

15. Lozano-Hemmer, "Best Practices for Conservation of Media Art”; Visual Media Workshop at the University of Pittsburgh, "Module A5: Project Documentation Checklist."

16. Geiger et al., "The Types, Roles, and Practices of Documentation"; Chassanoff and Post, OSSArcFlow Guide to Documenting Born-Digital Archival Workflows.

17. Edmond and Morselli, "Sustainability of Digital Humanities Projects."

18. Lozano-Hemmer, "Best Practices for Conservation of Media Art."

19. Vicky Steeves, “Investigating and Archiving the Scholarly Git Experience," IASGE. November 5, 2018. https://investigating-archiving-git.gitlab.io/about/.

2o. Edmond and Morselli, "Sustainability of Digital Humanities"; Lozano-Hemmer, "Best Practices for Conservation of Media Art"; Chassanoff and Post, OSSArcFlow Guide to Documenting Born-Digital Archival Workflows.

21. Lozano-Hemmer, "Best Practices for Conservation of Media Art."

22. Geiger et al., "The Types, Roles, and Practices of."

23. Geiger et al., "The Types, Roles, and Practices of Documentation."

24. Chassanoff and Post, OSSArcFlow Guide to Documenting Born-Digital Archival Workflows.

25. Lozano-Hemmer, "Best Practices for Conservation of Media."

26. Arthur C. Clarke, "Hazards of Prophecy: The Failure of Imagination," Profiles of the Future 6, no. 36 (1962): 1. 


\title{
Communicate
}

\section{Principle}

\begin{abstract}
xperiential scholarship exists within the same expectations and intellectual goals as traditional research and scholarship products. How a work of experiential scholarship meets those shared values and goals must be overcommunicated to peers and stressed by using language that highlights the analogous approaches.
\end{abstract}

\section{In Practice}

Reflecting the need for documentation, collaborators on a work of experiential scholarship should identify the discipline(s) to which the work will speak in order to utilize the norms and systems of those disciplines as a means of discussing the project and the work it does within the field.

This necessitates stretching the discipline's assumptions and contexts

- intentionally and effectively

- with documentary evidence to support the claims

- by communicating new forms of work that advance a discipline's core values and goals

Abigail Mann researched and prepared several guides in which she outlines the following considerations when working to communicate an experiential scholarly work to peers. ${ }^{1}$ One must:

- Explain the decisions and choices to make nontraditional experiential scholarship.

- Why is this form the most necessary for this work? 
- Connect to academic and/or disciplinary standards.

- How is this work validated or evaluated by peers?

- Point to what is new or innovative about the approach.

- In what ways does this expand an understanding of

"visualization," for example?

- Define and describe the meaningful artifacts of the work.

- Where might a reader/viewer encounter the component parts of the work?

- Offer specific options, processes, or tools for evaluation.

- How can I judge the quality of something I've never seen before?

\section{Case Study from Immersive Scholar}

This section, and those that follow, vary somewhat from that which we have established in the previous three chapters, although we are retaining the now familiar structure. Our focus in Immersive Scholar was on the creation of the experiential scholarship objects and the issues of credit, decoupling media, and documentation that arose in that creation. However, because we worked primarily with artists and designers, whose output is the media into which experiential scholarship is just venturing, there was relatively little concern about how to communicate the intent and impact of their work to their peers. Such is not the case in traditional academic disciplines, in which experiential work is opening new ways of arranging and sharing data, information, and ideas. In these fields, the issues we have highlighted are, of course, crucial, but must be paired with an existential threat: such work is often not counted or valued equally in evaluation leading to tenure and promotion. Without this institutional support, it is less likely scholars, particularly junior scholars, will engage in it.

Mann's work, referenced above, was the response to this realized need. For libraries to effectively foster experiential scholarship, they must foster an ecosystem in which such works can be published and reviewed in venues that are considered "appropriate" for academic evaluation, such as tenure and promotion. This can take the form of alternative forms of publication and display, but from the practical level it can also take the form of creating narratives and language that allow new works to be evaluated through old criteria. Each of the previous sections aims at a particular issue within this problem set: credit focuses on both documenting and normalizing labor outside of the expected monograph, decoupling makes an argument 

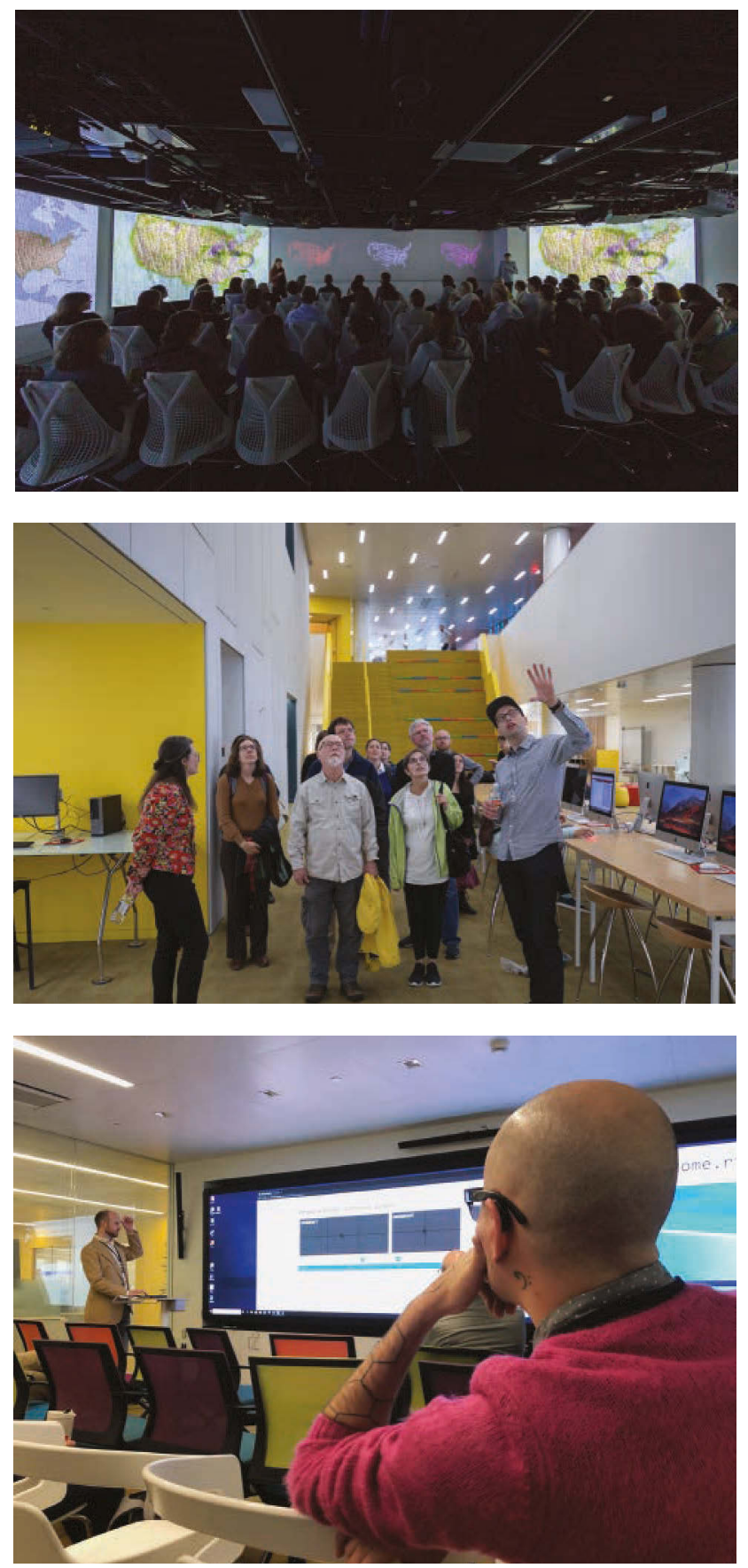

Various forms of communicating, through presentation, explanation, and demo. Photographs by Brent Brafford and Micah Vandegrift 
for thinking about and validating the forms in which such work appears, and documentation stresses the importance of creating an archive of this labor and these decisions. This section, then, highlights the principles undergirding the specific language suggestions in "Keywords for Discussing New Scholarship for Tenure and Promotion" and the larger theoretical shifts argued for in "Supporting New Scholarship."

Our case study here is the larger conversation happening in academia right now, particularly in enterprises such as the digital humanities and open science, in which discussions about how this thing counts or not on a CV and in a tenure portfolio regularly emerge. ${ }^{2}$ Moving beyond the fact of the need itself, our survey of the actions being taken by those actively practicing experiential scholarship reveals several trends. Disciplinary guidelines for evaluation of digital works like those from the Modern Language Association or College Art Association have offered a way forward, but without "publication" venues, experiential works continue to offer limited rewards for those working within academia.

The digital humanities have adapted to this space by forming apparatus that serve as clearinghouses for digital-first works. The newly formed Reviews in $\mathrm{DH}$, for instance, publishes project documentation alongside a peer review. This offers a venue for review and publication for digital-only work. The handbook from Duke University's Wired! Lab, Visualizing Objects, Places, and Spaces, offers a similar publication environment, releasing case studies of various digital scholarship formats - spatial, temporal, narrative, dimensional, and more. Each of these apparatuses lend an air of published-ness, allowing a scholar/creator to argue for the value of the work by pointing to text-based descriptions of complex multifaceted works. While we affirm these as necessary, good, and progressive (Immersive Scholar was submitted to and published in Reviews in $\mathrm{DH}$ ), there is still a distance between a description of the work and the work itself.

\section{Discussion}

If the case study reveals the difficulties of recognition and publication venue, it also reveals a striking absence: the role of the academic library. Libraries that work with researchers or scholars to produce experiential works must share the responsibility for communicating the intellectual and scholarly position a distinct project will hold. Knowing the shape of the field allows libraries to help practitioners structure their communications to speak to the 
not yet fully realized discourse around experiential scholarship. As content developers and technical liaisons, librarians must also embrace the role of gallerist or curator, exercising responsibility for the promotion, distribution, and critical reception of works we co-create. The principles of credit, decoupling, and documentation all undergird the possibility that an experiential, large-scale, or immersive visualization project could be "published," in the traditional sense of the word, but that there are not yet containers (e.g., journals, monographs, repositories) that could realize this fully.

Two criteria reign supreme in the reception of scholarly works qua scholarship: peer review and prestige, as marked by the venue of publication (e.g., Oxford University Press, Nature). Through the Immersive Scholar project we developed conceptual parameters for peer review (see appendix) combining technical, aesthetic, and display aspects in addition to the content. Possible venues for publishing (making public to a discrete scholarly community) are sparse, with examples like an exhibition at the IEEE Vis Arts Program, or design or media art collections like the New Museum/Rhizome's First Look: New Art Online. In light of the fact that these works are often built by, for, and in libraries and museums, and not always built by, for, or in fields of media, design, and the arts, we foresee a time when the prestige/publication could be married to the "performances" of these works in other libraries and museums, documented as provenance. The venue of prestige publication for an experiential work, then, is a web of screens, caves, walls, and web portals governed by the interests and excitement of local librarians.

Librarians must also serve as cheerleaders and coaches for recasting thinking and communication about where and when experiential scholarship manifests. Experiential scholarship engenders a new form of simultaneity. Using a digital humanities project as a straw man example, generally the academic purpose and audience for the project is primary, both in justification and chronology. Thus, a monograph may lead to a commercially successful trade copy, or a journal article could inspire a piece of science journalism. Experiential scholarship, in contrast, is always already consumed and recognized in the public sphere even as it is grounded in academic questions and genres.

In its decoupled forms, experiential scholarship is located simultaneously in public, commercial, and academic spaces and each space is equally primary. The challenge for the academic to communicate the value of this work to their peers is the innate aesthetic accessibility of the project, arising from the ubiquity of technology and increasing integration of experiential 
works into the fabric of the web. Scholars then must overcommunicate the intellectual depth of their work so that it is not overshadowed by its popular accessibility. Libraries play a crucial role in not just providing those spaces of simultaneity but helping to conceptualize them and how they are communicated. The vision we hope to cast with the principle of communication is that there is extraordinary potential for this form of scholarly product to exist outside the current academic publishing industry, which is fraught with legacy, not to escape such standards but to reshape what modern or future scholarship could look like in a blended physical/virtual/published ecosystem. We are still in the middle state where we have to talk about these projects using the language of traditional forms, but the collaborations we undertook in Immersive Scholar point toward the fissures in that language. As community engagement becomes increasingly valued in research and scholarship, we believe that experiential works, communicated well, play a foundational role in remaking that system.

\section{What You Can Learn from Us}

- Publishing apparatus for experiential scholarship products must be actively sought or created.

- Special attention must be paid to justifying the scholarly value of works aimed at larger audiences. ${ }^{3}$

- Libraries must play a role in finding homes for experiential scholarship, which can be in the form of

- Hosting projects and their archives

- Remaining aware of and advocating for new apparatuses for publishing works of experiential scholarship, and

- Encouraging the documentation of the credit and media choices of projects to prepare projects for future "containers."

Libraries, then, are not solely curators of already extant scholarship (i.e., collections and acquisitions); instead, like museums, they create cultural value through commissions and curation of supportive apparatus and do so with an understanding of future values of experiential scholarship while also recognizing the needs and calls of the "home" discipline that the work comes from. 


\section{Several Key Themes Emerge from the Relevant Literature}

In the previous sections, references were offered that spoke to the broad claims of much of the suggested literature. This set of key themes emerges from a meta-analysis that seeks the ultimate causes for the regularly appearing language and justifications in the various disciplinary statements cited below. Thus, there are no specific references here; rather, we would argue this set of concerns undergirds the practical suggestions in the texts in the Resources section.

\section{Clearly Define the Scope}

Experiential scholarship is not meant be a flourish but rather an essential part of building an argument or assembling data. It should be clear that approaches offer an enlarged vision of data, whether in scope, in handling, or in analysis; integrate various forms of data for the purpose of developing the argument or utilize new forms of presentation to reach new audiences or reshape arguments; or offer a new vantage point on an old problem by asking questions or approaching analysis in a new way, often drawn from different disciplines or fields.

\section{Explain the Need for Tools and Methodologies}

It is critical to communicate the way in which new or unusual tools and methodologies are an essential part of building an argument or assembling data. Language should explain the specific ways in which the methodology enlarges the data collected, how it is handled, or what argument can be made from it and how it can be shared. It is also necessary to narrate the intellectual labor of developing these tools or methodologies and researching the best practices associated with it; these are methodological achievements in line with traditionally understood ones. Equally, the labor done to secure funding for developing new tools and managing their development should be a standard part of the communication to peers.

\section{Define and Seek Appropriate Forms of Review and Reviewers}

Discussion of what counts as a standard of quality should be built into experiential scholarship in the early stages and clearly explained in proposals, research plans, and reports. Plans should also be made to involve experts from the fields of the media(s) used in the research, who can evaluate the modes and effectiveness, as well as those from the home discipline, who can speak to the structuring questions and focus. 


\section{Resources We Found Particularly Useful in Forming These Ideas}

College Art Association and the Society of Architectural Historians Task Force to Develop Guidelines for Evaluating Digital Art and Architectural History for Promotion and Tenure. "Guidelines for the Evaluation of Digital Scholarship in Art and Architectural History." CollegeArt.org, last modified 2016. https://www .collegeart.org/pdf/evaluating-digital-scholarship-in-art-and-architectural -history.pdf/.

"Draft-New Criteria for Tenure and Promotion USF School of Art and Art History." University of Southern Florida, last modified March 2015. https://www .usf.edu/arts/administrative-resources/documents/tenure-promotion/saah -tp-guidelines.pdf.

Ellison, Julie, and Brett Eastman. Scholarship in Public: Knowledge Creation and Tenure Policy in the Engaged University, 2008. http://imaginingamerica.org /wpcontent/uploads/2015/o7/ScholarshipinPublicKnowledge.pdf.

"Guidelines for Evaluating Work in Digital Humanities and Digital Media." MLA. org, last modified 2012. https://www.mla.org/About-Us/Governance /Committees/Committee-Listings/Professional-Issues/Committee-on -Information-Technology/

Guidelines-for-Evaluating-Work-in-Digital-Humanities-and-Digital-Media.

"Guidelines for the Professional Evaluation of Digital Scholarship by Historians." Historians.org. Accessed June 2019. https://www.historians.org/teaching-and -learning/digital-history-resources/evaluation-of-digital-scholarship-in-history /guidelines-for-the-professional-evaluation-of-digital-scholarship-by-historians. Lawley, Elizabeth L. "Publication and Evaluation Challenges in Games and Interactive Media." RIT Scholarworks. Accessed October 9, 2020. https://scholarworks .rit.edu/other/919/.

"Portland State University General Tenure Statement." Portland State University, last modified 2014. https://www.pdx.edu/faculty-senate/sites/www.pdx.edu .faculty senate/files/PT\%20Guidelines\%20\%204-23-2014.pdf.

"Selecting and Supporting Graphic Design Faculty." National Association of Schools of Art and Design, last modified 2016. https://nasad.arts-accredit.org /wp-content/uploads/sites/3/2016/03/AIGA_NASAD_Graphic-Design -Faculty.pdf. 


\section{Reflections}

\section{Communication to Peers - Abigail Feldman}

Experiential scholarship should be directed toward the public. Decoupling demonstrates that it is presented in different modes and media to increase access. Experiential scholarship's communication system has the potential to help make academic research more transferable and usable. ${ }^{4}$ These qualities are critical to the current moment in which scholarship for the sake of knowledge is at risk of becoming scholarship for profit. Experiential scholarship is uniquely positioned to help resist control and capitalization of scholarship by making possible and normalizing a model of scholarship whose form inherently pushes against numerical metrics of value. To create an ecosystem of scholarship that is both freely accessible and ethical, alternative publishing networks must embrace questions of financing, ownership, and values. ${ }^{5}$ In turn, scholars and researchers must be responsible for seeking out new means of validating alternative forms of scholarship. There must be communication between peers.

To speak to a community of scholars, an aesthetic of access must be directed to account for another participant: academia. Experiential scholarship calls for new ways of speaking about scholarship, but if those ways can be made analogous to the current language of academia, new forms of value can be cultivated and acknowledged in already existing systems. To develop common systems for validation, scholars must work together in a community of practice. The work of Immersive Scholar ties together the principles of contributorship, decoupling, documentation, and communication to fully come to bear on the development of a community of practice among peers in experiential scholarship.

Experiential scholarship is still new. There aren't uniform standards as to how the different principles should be carried out, and because each experiential scholarship project is unique in both content and technology, to truly be accessible, there shouldn't be a single set of standards. Rather than conceiving a prescriptive structure, Immersive Scholar aids in the formation of a community of practice through the development of a common language and best practices that are not rigorous standards but approaches that work to translate invisible theoretical values and underpinnings to visible practices. "The Raleigh Statement on Good Practices for Developing Experiential 
Scholarship Projects" arms those developing projects with questions to ask themselves, technologies and communities to consider, and values to strive for. "Supporting New Scholarship: Why and How," compiled by Abigail Mann under Immersive Scholar, gives insight to both scholars and institutions on the unique, situated value of experiential scholarship as an ecosystem of knowledge presentation and growth. "Keywords for Discussing New Scholarship for Tenure and Promotion" gives scholars an explicit language to use to convey that value to traditional academic audiences. These products are not temporally bound in their development nor in their practical use. They are versions developed concurrently with scholars in residence developing their experiential scholarship projects, and they can continue to evolve in tandem with the field as a whole. It would be ideal to integrate these practices throughout the development, dissemination, maintenance, and growth of experiential scholarship projects, but encountering them at a later stage, or even retrospectively, gives scholars access to language to talk about their work, a community to exchange knowledge with, and practices to implement moving forward.

Experiential scholarship projects have to wear many hats. An aesthetic of access may question to what end? For all of it? The answer is knowledge. Each principle is meant to provide support to the potential of experiential scholarship knowledge and the creation of new forms of knowledge: alternative presentations of knowledge, knowledge that simultaneously intimately involves the public and is validated by the academic community, and knowledge that can grow. The work of Immersive Scholar and the principles laid forth act in service of forms of knowledge that attempt to renegotiate who and what scholarship is for.

Disruption, Recovery, and Care:

Peer Communication - Cynthia Rosenfeld

The principle of peer communication in experiential scholarship brings us back full circle to the principle of contributorship. Digital and posthumanities scholar Roopika Risam would remind us that the communities of scholars most likely to have their experiential scholarship work undervalued are those who interrogate what "human" is presumed in the humanities: Black studies, ethnic studies, postcolonial studies, women's studies, and queer studies, to name a few. ${ }^{6}$ Recovering the experiences of people whose stories have been marginalized (see, for example, the University of Houston's "Re- 
covering the U.S. Hispanic Literary Heritage Project") is an act of care and a disruption to the Enlightenment model of the human-ities, and supporting the scholars engaged in these acts of recovery requires careful peer communication. Two issues concerning careful peer communication and experiential scholarship immediately come to mind: (1) how the stakes and contributions of experiential scholarship get communicated to a wide academic audience, and (2) how experiential scholarship can retain the best aspects of peer review in project development.

First, there is the issue of communicating experiential scholarship contributions to academic audiences. In New Digital Worlds, Risam describes the perpetual crisis that people in the humanities experience owing to an ongoing, false distinction that bifurcates the humanities from the sciences and privileges the sciences. To make matters more difficult for experiential scholarship, many experiential scholarship projects are - as Angel David Nieves described in a keynote address at the Immersive Pedagogy symposium - iterative in nature, often deliberately incomplete, and frequently narratively rich. ${ }^{7}$ In a "publish or perish" environment, there is a challenge to articulate the significance of projects that emphasize process. Thus, humanities scholars involved in experiential scholarship projects may experience layers of scholarly marginalization. Further, scholars in the humanities and sciences may find themselves needing to articulate the significance and stakes of multiple experiential scholarship projects (which gets characterized more as knowledge visualization), which would not have to be articulated through multiple journal articles (which gets characterized as knowledge generation).

Janneke Adema and Gary Hall ask if we can rethink how we understand knowledge generation, performances, and visualizations when they pose the following questions:

Is it possible to envision the seminar as both part of the research process (instead of merely a re-presentation of the research)?

Could we even arrive at a situation where a researcher can spend their whole career giving the "same," endlessly updated, and so never fixed and finalized, paper?

To pursue this line of thought still further,

Should more emphasis be placed on the critical engagement that occurs around and as part of a presentation $?^{8}$ 
Adema and Hall were asking these questions of conference presentations, but they apply just as well to experiential scholarship projects in all their instantiations. The peer communication section of this guidebook gives useful recommendations for how to highlight and communicate the significance of experiential scholarship projects to hiring, tenure, and promotion committees, but in the spirit of disruption and care, we pose different questions here:

How are departments and universities supporting and encouraging experiential scholarship projects?

Are there opportunities for mentorship and peer evaluation?

How are experiential scholarship projects evaluated by tenure and promotion committees?

How are experiential scholarship projects considered among job candidates?

To what extent is experiential xcholarship part of pedagogy?

The second issue of careful peer communication was just mentioned: How are scholars in experiential scholarship receiving the support of peer evaluation? Although there are many debates in the area of peer review (e.g., should reviewers be anonymous or named? How should biases among reviewers be detected and addressed? What recourse should authors have in response to peer reviews?), peer review is still a hallmark of scholarly work and, in the best of circumstances, brings awareness to blind spots and helps manuscripts with clarity and coherence. Scholars engaged in experiential scholarship projects need peers who can help them develop their projects, bring awareness to blind spots, and help with clarity and coherence.

In the vMLK project, two humanities advisors were brought on board early in the project's development to critique and evaluate. Unlike examples of passive boards, the advisors were involved in workshops and helped the principle investigators to develop their approach to the project. Bringing the advisors in early gave them the opportunity to have more substantial contribution to the direction of the project. Risam describes that part of the work of critical scholars in the digital humanities is to intervene in the digital cultural record and to, as Kim Gallon would say, recover the peoples and stories who have been marginalized. One reason that departments and universities need to support experiential scholarship is so experiential scholarship scholars have peers to help them develop their interventions in the digital cultural record. 


\section{Notes}

1. Abigail Mann, "Keywords for Discussing New Scholarship for Tenure and Promotion," Immersive Scholar, Micah Vandegrift, Shelby Hallman, Walt Gurley, Mildred Nicaragua, Abigail Mann, Mike Nutt, Markus Wust, Greg Raschke, Erica Hayes, Jasmine Lang, David Reagan, Eric Johnson, Chris Hoffman, Patrick Rashleigh, Robert Wallace, William Mischo, Elisandro Cabada. Released on GitHub and Open Science Framework, accessible at https:// osf.io/kbj7d/; and "Supporting New Scholarship: Why and How," Immersive Scholar, Micah Vandegrift, Shelby Hallman, Walt Gurley, Mildred Nicaragua, Abigail Mann, Mike Nutt, Markus Wust, Greg Raschke, Erica Hayes, Jasmine Lang, David Reagan, Eric Johnson, Chris Hoffman, Patrick Rashleigh, Robert Wallace, William Mischo, Elisandro Cabada. Released on GitHub and Open Science Framework. https://osf.io/nk7w4/.

2. There is a wide-ranging discussion of this issue. See, for instance, Sarah E. Ali-Khan, Liam W. Harris, and E. Richard Gold, "Motivating Participation in Open Science by Examining Researcher Incentives,” ELife 6 (2017). https://doi.org/10.7554/eLife.29319; Paul Ayris, Alea López de San Román, Katrien Maes, and Ignasi Labastida, Open Science and Its Role in Universities: A Roadmap for Cultural Change (LERU, 2018). https://www.leru.org /publications/open-science-and-its-role-in-universities-a-roadmap-for-cultural-change; "DH in Tenure and Promotion," accessed July 31, 2019. https://digitalhumanities.group.ufl .edu/dh-uf/tenure-promotion/; "Evaluating Digital Scholarship | NINES/NEH Summer Institutes: 2011-2012," accessed June 19, 2019. http://institutes.nines.org/; Cathy Davidson, "How Can a Digital Humanist Get Tenure?” HASTAC, accessed July 31, 2019. https://www.hastac .org/blogs/cathy-davidson/2012/o9/17/how-can-digital-humanist-get-tenure; Sidney Dunn, "Digital Humanists: If You Want Tenure, Do Double the Work," ChronicleVitae for Higher Ed Jobs, Career Tools and Advice, accessed May 28, 2019. https://chroniclevitae.com/news/249 -digital-humanists-if-you-want-tenure-do-double-the-work; National Academies of Sciences, Engineering, and Medicine, "Advancing Open Science Practices: Stakeholder Perspectives on Incentives and Disincentives: Proceedings of a Workshop-in Brief" (Washington, DC: The National Academies Press, 2020). https://doi.org/10.17226/25725; Arlene Stein and Jessie Daniels, Going Public: A Guide for Social Scientists (Chicago: University of Chicago Press, 2017).

3. Abigail Mann, "Keywords for Discussing New Scholarship."

4. Alyssa Arbuckle and Bonnie Stewart, "How Can We Make Scholarship More Relevant?” InsideHigherEd \#Blogs, November 13, 2017. https://www.insidehighered.com/blogs /university-venus/how-can-we-make-scholarship-more-relevant.

5. Andrea E. Pia et al., "Labour of Love: An Open Access Manifesto for Freedom, Integrity, and Creativity in the Humanities and Interpretive Social Sciences," Commonplace, July 16, 2020. https://doi.org/10.21428/6ffd8432.a7503356.

6. Roopika Risam, New Digital Worlds: Postcolonial Digital Humanities in Theory, Praxis, and Pedagogy (Evanston, IL: Northwestern University Press, 2019).

7. Angel David Nieves, Developing a Social Justice Framework for Immersive Technologies in Digital Humanities. Lecture, accessed June 17, 2020. https://www.youtube.com/watch?v =zsJQg69nB $90 \&$ list $=\mathrm{PLbkhiRA}_{2} \mathrm{P}_{3} \mathrm{IIPV}_{5} \mathrm{hrdVmIwWN}_{3} \mathrm{l}_{\mathrm{cEiKzy}}$.

8. Janneke Adema and Gary Hall, "Posthumanities: The Dark Side of 'The Dark Side of the Digital," Journal of Electronic Publishing 19, no. 2 (October 1, 2016). https://doi.org/10.3998 /3336451.0019.201. 
This page intentionally left blank 


\title{
Conclusion
}

\begin{abstract}
he principles and practices approach we model herein is meant to provide flexibility and offer a loose framework in which many kinds of work can fit. We concur with our colleagues in the Humane Metrics Initiative in stating that we hope to "set the stage for a values discussion by prioritizing the processes of academic labor instead of the products." Experiential scholarship is an interpretive translation process through which practitioners, producers, and various publics can be co-located and attentive in a work of scholarship. The final challenge, as exists for much of academic knowledge, is in welcoming, inviting, and making meaningful things for our neighbors whose lives are busy and full. The following reflections engage with this challenge. Are we bold enough to claim that experiential scholarship presents possibilities for public impact in ways that most other works cannot?
\end{abstract}

\section{Reflections}

Communication to/with Public-Abigail Feldman

While the principle of decoupling positions technology as an apparatus of a networked experiential scholarship, the principle of interpretation positions the public as an active actor within and beyond the network. Interpretation emphasizes an intentional, informal extension of an experiential scholarship network and knowledge to the public. An aesthetic of access leads us to inquire: "to what end?" What is the value to the public, how does their engagement enhance the experiential scholarship network, and how can these relationships be manifested and supported?

Experiential scholarship can empower audiences to see themselves as participants. It is scholarship that is meant to be experienced; communicated as not just a scholarly narrative but a public narrative. ${ }^{2}$ If scholarship is 
shared with the public in a way that acknowledges that they are intimately involved in it, it may change the way they respond to the information that is being presented. This is a shift in deep memetic frames - ways of being and seeing that direct someone's attention to some things but not others. These frames prime people to respond to information in certain ways. They are maintained by our words and actions, and the words and actions of others in our networks. ${ }^{3}$ Experiential scholarship offers a new way for scholarship to be, and to be seen. How it will exist and be seen will vary from project to project, but as long as it is framed so that the public directs attention to it, and feels involved, it can become a relevant part of the local cosmology: their conception of what the world is like and how they fit within it. ${ }^{4}$

Of course, a person's local cosmology is broader than their position within the experiential scholarship information network. To understand the implications an experiential scholarship project may have, we have to consider how the ever-expanding information network may permeate through the audiences' own networks. This in turn calls us to consider what else the audience is beholden to. Rebecca Solnit posits that people are beholden to each other; that society itself is its own network of deeply entrenched commitments and connections between people, families, and groups. ${ }^{5}$ Whitney Phillips extends this concept of ecological existence to include a network not only of people, but of text, platform, and publication simultaneously growing in the digital world as well as the physical. So just as each part of experiential scholarship is influenced by its relationships with the other parts of its network, if an experiential scholarship project becomes a part of a person's own network or local cosmology, it can influence the other connections that person has.

The potential for an experiential scholarship network to expand through public networks is baked into the work of vMLK, which centers the practice of "participatory readiness." Participatory readiness is a concept that calls for education that prepares students to engage in civic and political action in their communities. ${ }^{6}$ The vMLK project historicizes King in a broader moment than just White Rock by making it generational. The project creates a connection between the past and present by presenting a speech that addresses concepts, ideas, and problems not only of the time, but which are also relevant today. ${ }^{7}$ Presented in this context, the experience of vMLK embodies transformative education that encourages students to connect with the past and attempts to prepare them to take civic action in the present. The project recognizes and supports an ethos of participatory readiness in its audience 
through "Your Creative Protest." This extension of the project encourages reflective action, a form of practice for participation on a larger scale, outside of the boundaries of the project.

The networks of our local cosmologies are complicated webs, and while it may be impossible to fully trace their connections with experiential scholarship networks, acknowledging early on in the development of an experiential scholarship project that the work will extend through the public gives scholars an opportunity to deeply consider the potential how's.

\section{Disruption, Recovery, and Care:}

\section{Communication with Publics - Cynthia Rosenfeld}

The activities of disruption, recovery, and care are perhaps nowhere more consequential than in communication with publics. When we think about public engagement in experiential scholarship, we have to attend to questions of how our artifacts are going to live with the communities they engage and what those artifacts are likely to do with different publics. These questions involve attention to methods/processes, ethics, and a review process that exceeds peer review and welcomes a $360^{\circ}$ review that includes community advisors.

Consider, for example, what it would mean to recover Sojourner Truth's 1851 "Ain't I a Woman?" speech. A first step in recovery is to disrupt the cultural record of this speech. Many Americans grew up knowing this speech as the "Ar'nt I a Woman?" speech. The "Ar'nt I a Woman?" transcript comes from Frances Gage's 1863 version of the speech published in the New York Independent. This version attributes "a southern slave dialect” to Truth's speech (Sojourner Truth Project, "Compare the Speeches"). Truth, born in New York and whose first language was Dutch, would not have had a Southern dialect. There is another version of the speech, though. Just twelve days after Truth delivered her speech, her friend and journalist Marius Robinson published his transcript of the speech in the Anti-Slavery Bugle, and according to the Sojourner Truth Project, Robinson and Truth went over his transcription before it was published. (You can read the transcription and the 1863 version side by side at Compare the Speeches. $)^{8}$ After selecting and recovering the Robinson transcript, then what? How could one produce an audio recording that recovers (and cares) when we don't know Truth's voice? The answer, for The Sojourner Truth Project, is embracing the multiple and engaging the community. The project's site offers multiple readings of the Robinson transcript from Afro-Dutch women. The site acknowledges 
the contributions of these readers, and - as an open source project - invites publics to submit readings, work on the website, or share additional research.

If we are to heed Risam's call and disrupt the digital record by recovering the stories of people who have been marginalized both online and offline we have to be careful. The Sojourner Truth Project is not an Immersive Scholar project but is an illuminating example of the principle of communication with publics via how care was enacted through the recovery of the Robinson transcript, allowing publics to participate in recovery by offering readings or otherwise contributing to the project.

The VMLK project is a partner of Immersive Scholar and also sheds light on the practice of communication with publics. Like The Sojourner Truth Project, the publics are not understood as passive audiences who undergo an experience. Rather, they are actively involved in the doing of an experience (cf. John Dewey's “Art as Experience," 1934/1980). ${ }^{9}$ In the vMLK project, we see how the community of White Rock Baptist Church was brought into the making of the project, as they were the participatory audience for Marvin Blanks's performance of Dr. King's "A Creative Protect" speech. Further, in the most recent documentary video of the project, members of White Rock contribute to our understanding of what the speech does with them by sharing their impressions, experiences, and interpretations of the project. Many of the project's collaborators speak to how the project came to be, but the members of White Rock speak to how the project lives in a community that cares.

There are many challenges in communicating with publics. Even if you want to have public(s) involvement, it is not a given that anyone will want to participate. As anyone who has taught public speaking or English composition is likely to say, you have to earn their attention. Talk to your public(s) about your plans for an affirmatively disruptive experiential scholarship project and listen to their needs. Look and listen for what needs to be recovered and how, and know that what needs to be recovered often won't be stated explicitly. A person could not request a recovery of Dr. Christine Mann Darden's contributions to aerodynamics when she had, until recently, been so well hidden in the cultural record that many did not even know there was a Dr. Darden story to be recovered. ${ }^{10}$ Communicating - an ongoing process - with publics is both a means and an end of experiential scholarship. Stumbling will be involved, and humility will be essential. 


\section{Notes}

1. Penny Weber, "Humane Metrics Initiative-Website Relaunch," HuMetricsHSS (blog), August 11, 2020. https://humetricshss.org/news/website-relaunch/.

2. Alyssa Arbuckle, and Bonnie Stewart, "How Can We Make Scholarship More Relevant?” Inside Higher Ed (blog), November 13, 2017. https://www.insidehighered.com/blogs /university-venus/how-can-we-make-scholarship-more-relevant.

3. Whitney Phillips and Ryan Milner, “The Devil's in the Deep Frames." [internet], 2020. https://you-are-here.pubpub.org/pub/57so6mjw/release/2\#deep-memetic-frames.

4. Whitney Phillps, "Navigating the Information Landscape: A Media Literacy Toolkit Series," Commonplace, 2020. https://commonplace.knowledgefutures.org/pub/7xyfeg8b/release/1.

5. Rebecca Solnit, A Paradise Built in Hell: The Extraordinary Communities That Arise in Disaster (New York: Penguin, 2010).

6. Danielle Allen, Education and Equality (Tanner Lecture 2), (The McCoy Family Center for Ethics in Society: Stanford University, 2014).

7. This description of the work of vMLK comes from the July 2020 version of the vMLK project documentary.

8. Leslie Podell, The Sojourner Truth Project, accessed July 2020. https://www.thesojourner truthproject.com/compare-the-speeches/.

9. John Dewey, Art as Experience (New York: Perigee, 1934/1980).

10. Catherine D'Ignazio and Lauren F. Klein, "Introduction: Why Data Science Needs Feminism," in Data Feminism, edited by Catherine D'Ignazio and Lauren F. Klein (Cambridge: MIT Press, 2018). 
This page intentionally left blank 


\title{
Testing Guidelines for Immersive Digital Applications
}

\author{
DEVELOPED BY WALT GURLEY
}

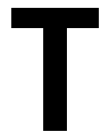

his document provides brief guidelines for immersive digital application creators and evaluators/testers to support sharing and testing of immersive digital content.

\section{Content creators}

This section includes recommendations for information that should be included in a documentation file (e.g., README file) for an application meant to be shared and used in an immersive display environment.

Documentation of an application should include a description of the application. This description should provide an overview of the application and its functionality. Any images that demonstrate the appropriate appearance and function of the application should be included.

\section{Hardware dependencies}

- Display type (on which device types will this application display properly?)

- Display size (Are there any considerations for display pixel size, display physical size, or display aspect?)

- Processing power and memory size (Are there any minimum requirements for CPU/GPU processing power or memory size?)

- Connectivity (Is an internet connection required?)

- Input devices (Does this application require input? Is this application interactive?) 


\section{Software dependencies}

- Operating system (On which operating systems will this application run?)

- A list of all software (including version numbers) required to run this application

\section{Installation instructions}

- A description of all steps an end-user must follow to install and run the application, including installation of dependencies.

\section{Contact}

- A contact for general questions

- A contact for troubleshooting questions

\section{Evaluators/Testers}

This section includes recommendations for information that should be collected during the evaluation of an immersive digital application. Information collection is partitioned between testing device specifications and application performance. A suggestion is to use forms to systematically collect each type of information.

Questions evaluation forms should include:

Form 1: Testing device specifications

1. What operating system are you running on your machine?

2. What are the specifications of the machine's processor?

3. What are the specifications of the machine's graphics processor?

4. If this is a web application, what browser (including version) do you run on your system?

5. What are the pixel dimensions of your display (px width $\mathrm{x} p \mathrm{px}$ height)?

6. What are the physical dimensions of your display (width $\mathrm{x}$ height)?

Form 2: Application performance

1. If this application requires any installation, did you encounter any issues installing this application or its dependencies?

2. Did the application launch appropriately?

3. Did the application appear appropriately on your display?

4. Are there any noticeable performance issues while running the application?

5. If this application includes interaction, did the interactive behavior perform appropriately? 


\section{Raleigh Statement on Good Practices for Developing Experiential Scholarship Projects}

Developed by the Immersive Scholar Cohort at the Liberact V conference, November 15, 2019

W e, the Immersive Scholar Cohort*, gathered at Liberact on Nov. 15th, 2019, compiled the following as guidelines for communities of practice in the broad area of "academic visualization", including large-scale, immersive, virtual, extended, and augmented reality, digital/ web-based art, software development, GIS, spatial humanities, experiential, experimental, and expansive scholarship, and other related forms of expression and intellectual effort. We present this as our current understanding of the landscape, based in part on the collaborative project we have conducted these past three years, but not in any way the end-all, be-all of this area of work.

Version 0.1 of this document is captured and collected in the Immersive Scholar documentation portal - https://osf.io/ $5583 \mathrm{~h} /$.

* 11 white men with university positions and one Latinx project manager on contingent part-time funding

\section{Regarding Visualization/VR Support groups;}

- Identify your mission/objectives clearly from the start

- What technologies do you want to support? e.g., large walls, VR, AR, photogrammetry, advanced media, Web, some/all of the above 
- What domains do you want to support? e.g., specific departments on a grant, science/engineering departments, all departments/domains

- What types of users do you want to support? e.g., novices, experts, in-between; faculty, staff, undergrads, grad students

- What constitutes "success" at your institution? e.g., number of users, number of domains, number of publications/formal exhibits, number of grants, number of academic courses utilizing tech, etc.

\section{Regarding Skill Development;}

- Training for new visualization professionals should be technical and aesthetic

- Multifaceted approach to instruction:

- Instruction for researchers to integrate the technologies into their research methodologies to answer their research questions

- Instruction (i.e., workshops) for "beginners" or the new user, with a curriculum framed for that audience

- Instruction for class instructors on how to integrate the technologies into their coursework

- Leverage existing talent pipelines within the Library and Information Science field

- Urging new skills to be introduced into the LIS field

- three.js

- Node

- Angular/React/Vue

- $\mathrm{d}_{3}$

- A-Frame

- WebXR API

- WebAssembly

- Unity/UE

- Modeling/CAD

- Python

- Fundamentals of vision, perception, and user experience

- Basics of graphic design

- Leverage interest amongst students who want to develop these skills, and know that their ability to contribute will vary significantly

- Look for skills and expertise in diverse corners because visualization technologies are in use in different places (like medicine and architec- 
ture), and the skills required are actually very diverse (incorporating design, software, hardware, engineering, and domain expertise).

- Tied to diversity and inclusion in developers, creators, and thinkers in this area

- Public engagement and outreach to underserved and underrepresented communities is critical to minimizing the potential for widening the digital divide through the focus on immersive technologies

\section{Regarding Documentation;}

- Should be compiled before (MOU), during (code, data management, contributions) and after (narrative) and shared as essential project artifact compiled with software, data, and/or executables

- Include information on device types, screen sizes, screen aspect on which your application is expected to display correctly

- Manage expectations, understand your bandwidth, and document/ communicate what you are able to support

- Include a visual record of ideal output (e.g., a video of the output) in order to know "what it should look like"

- Consider what policies for usage may apply to particular visualization spaces

- Strong preference for documentation to be compiled in open source file formats, e.g., txt, md, csv

- "Human"-oriented technical documentation (i.e., not auto generated)

- Document your commitment to equity, diversity, and inclusion and promote those values through the projects you support

\section{Regarding Visualization Technologies;}

- Low barrier of entry for user experience is paramount

- i.e., Indiana University IQWalls, Glider; should be able to scale up or down to a "kit of parts" for maximum accessibility

- Expect changes

- Expect different use cases at different institutions

- Access to the tools and technologies should not be a barrier to access the content; design for maximum extensibility, which may mean lowest common denominator

- Deviation from standard practices (e.g., aspect ratios) will increase 
complexity of content development and limit the ways in which content can be shared

- Be aware of the tiers of tool complexity

- Map expectations to different levels of resources. So: what can you do with Powerpoint? (for walls) ... What can you do with a web stack? (a-frame in VR) ... What can you do with Unity?

- Have awareness of each tier - e.g., PPT/Keynote are often quickly dismissed, but they are underutilized in terms of animations, etc.

- Be aware that visualization technologies are currently very proprietary and competitive. Open standards do not exist. Mitigate this by promoting standards as they emerge, producing intermediate or derivative outputs (e.g., $\mathrm{MP}_{4}$ videos of experiences, open formats of intermediate results).

\section{Regarding Open Licensing;}

- As open as possible, as closed as necessary, in software, data, documentation, and executables

- Default to MIT, if no other preference

- Visualization content/projects should be openly licensed so that it can be reused and adapted easily in different contexts

- Code should be open licensed so it can be modified

- Check your institution's intellectual property policies. Make the case for the most open license possible

\section{Regarding Marketing/Promoting;}

- Sharing project examples can help unfamiliar users learn what a technology can do

- Providing clear documentation for users with varying levels of expertise will help promote adoption beyond uses by technical experts

- Visualization projects should be marketed according to the norms of the community most connected to the content, not the platform/ technology, or the producing institution

- Be aware that the agenda for a technology program can be driven by the optics of wow factor 
- Don't be afraid of stating that wow factor is a goal; having a clear understanding about that can change the desired outcomes

- Encourage local "visualization champions" to be key parts of marketing/promotion

\section{Regarding Project Development/Management;}

- Visualization projects require time and money. Investment in project development means hiring people, training them, and providing them necessary resources

- Proper crediting of all those involved

- Utilize existing vocabularies for collaboration like TaDiRAH or the CRediT taxonomy

- Software developers need a strong skill base to be successful. Students leave

- Documentation of other successful/failed projects can help establish institutional support needs

- Develop a tiered service level for different types of intended users

\section{Regarding Content Development;}

- Visualization projects that combine a scholar, aesthetic expert (artist/ designer), and a technologist are ideal

- Develop strategic approaches that pairs faculty and key partners to unlock the potential of different collections or assets of the university

- Develop standards for your institution in terms of processes, outputs, and preservation

- Use content development as an opportunity to support faculty who seek to change promotion considerations to include digital work

- Provide the infrastructure, in terms of tools and services, that will allow domain specialists to build add-on custom content

- Bring in professional designers and artists (and their associated processes) to develop higher quality products

- Design content for multiple displays and consider responsive design approaches to make work more portable. Build testing into timelines and plans 
- Understand that performance issues can be very important and can take lots of time

- Consider what metadata standards would be appropriate

\section{Regarding Dissemination;}

- Academic visualizations are intellectual, technical, and political objects that are forms of knowledge creation. As such, academic best practices should apply, particularly "publishing” (to make public through recognized and common channels for the purpose of referenceability), and citation

- Use of existing communities of practice

- Sharing of content when appropriate through federated networks

- The web provides an effective and efficient means of distribution and provides the necessary infrastructure for dissemination of content

- Good practice is to deliver content in three simultaneous media - virtually (online), physically in a immersive space, and narratively, either through text, video, or presentation

- The web provides an effective mechanism for creating content for display across multiple screens and devices (i.e., responsive web design pattern)

\section{Regarding Validation/Certification;}

- Academic visualizations are intellectual, technical, and political objects that are forms of knowledge creation. As such, we must establish forms of

- "peer review/assessment",

- sites for curation,

- community-governed markers of quality (badges for extensibility, interoperability, remixability), and

- partnerships with publishers of shared values (University Presses, Society/Associations).

- Utilization of documented standards is an indirect type of "certification": W3 $\mathrm{C}$ (HTML5, WebXR, etc.), ISO (X, $\mathrm{X}_{3} \mathrm{D}$, etc.) 


\section{Regarding Sustainability;}

- Willingness to sunset, ability to maintain

- similar to other technology-based (or -dependent) projects

- Understand campus mission and seek alignment and visibility of your work

- Seek opportunities to do the next big thing using these emerging technologies. Someone on your campus has good ideas for visualizing their scholarship but needs help to make it happen

- Understand that in this space, there is a lot of experimentation which means that some results will not be successful or worth maintaining

- Understand the risks involved with these projects so that you know what you're getting into

- Be willing to say "no” (we can't support you) to users who will not follow documented best practices

- It is not about sustaining the use of a specific technology but addressing the research and instruction needs a technology had traditionally met

- Prototype as quickly and as cheaply as possible and pivot based on lessons learned

- Don't build spaces without adding labor to support them 
